\title{
Multimodal Mesoporous Silica Nanocarriers for Dual Stimuli-Responsive Drug Release and Excellent Photothermal Ablation of Cancer Cells
}

This article was published in the following Dove Press journal: International Journal of Nanomedicine

\author{
Vy Anh Tran ${ }^{1,2, *}$ \\ Van Giau Vo $\mathbb{D}^{3,4, *}$ \\ Kyuhwan Shim ${ }^{5}$ \\ Sang-Wha Lee $\mathbb{D}^{\prime}$ \\ Seong Soo A An (D) ${ }^{6}$ \\ 'Department of Chemical and Biological \\ Engineering, Gachon University, \\ Seongnam, Republic of Korea; ${ }^{2} \mathrm{NTTHi}-$ \\ Tech Institute, Nguyen Tat Thanh \\ University, Ho Chi Minh 700000, \\ Vietnam; ${ }^{3}$ Institute of Research and \\ Development, Duy Tan University, \\ Danang 550000, Vietnam; ${ }^{4}$ Department \\ of Industrial and Environmental \\ Engineering, Graduate School of \\ Environment, Gachon University, \\ Seongnam 13|20, Republic of Korea; \\ ${ }^{5}$ Department of Neurology, Veterans \\ Medical Research Institute, Veterans \\ Health Service Medical Center, Seoul \\ 05368, Republic of Korea; ${ }^{6}$ Department \\ of BioNano Technology, Gachon \\ University, Seongnam 13120, Republic of \\ Korea
}

*These authors contributed equally to this work
Background: Core-shell types of mesoporous silica nanoparticles (MSNs) with multimodal functionalities were developed for bio-imaging, controlled drug release associated with external $\mathrm{pH}$, and near-infrared radiation (NIR) stimuli, and targeted and effective chemo-photothermal therapeutics.

Materials and Methods: We synthesized and developed a core-shell type of mesoporous silica nanocarriers for fluorescent imaging, stimuli-responsive drug release, magnetic separation, antibody targeting, and chemo-photothermal therapeutics. Also, the biocompatibility, cellular uptake, cytotoxicity, and photothermal therapy on these FS3-based nanocarriers were systematically investigated.

Results: Magnetic mesoporous silica nanoparticles was prepared by coating a $\mathrm{Fe}_{3} \mathrm{O}_{4}$ core with a mesoporous silica shell, followed by grafting with fluorescent conjugates, so-called FS3. The resulting FM3 was preloaded with therapeutic cisplatin and coated with polydopamine layer, socalled FS3P/C. Eventually, graphene oxide-wrapped FS3P/C (FS3P-G/C) exhibited high sensitivity in the dual stimuli (pH, NIR)-responsive controlled release behavior. On the other hand, $\mathrm{Au}$ NPs-coated FS3P/C (FS3P-A/C) exhibited more stable release behavior, irrespective of $\mathrm{pH}$ changes, and exhibited much more enhanced release rate under the same NIR irradiation. Notably, FS3P-A/C showed strong NIR absorption, enabling photothermal destruction of HeLa cells by its chemo-photothermal therapeutic effects under NIR irradiation $(808 \mathrm{~nm}, 1.5$ $\mathrm{W} / \mathrm{cm}^{2}$ ). The selective uptake of FS3-based nanocarriers was confirmed in cancer cell lines including HeLa (American Type Culture Collection - ATCC) and SHSY5Y (ATCC 2266) by the images obtained from confocal laser scanning microscopy, flow cytometry, and transmission electron microscopy instruments. Cisplatin-free FS3-based nanocarriers revealed good cellular uptake and low cytotoxicity against cancerous HeLa and SH-SY5Y cells, but showed no obvious toxicity to normal HEK293 (ATCC 1573) cell.

Conclusion: Along with the facile synthesis of FS3-based nanocarriers, the integration of all these strategies into one single unit will be a prospective candidate for biomedical applications, especially in chemo-photothermal therapeutics, targeted delivery, and stimuliresponsive controlled drug release against multiple cancer cell types.

Keywords: mesoporous silica NPs, Au NPs, stimuli-responsive drug release, chemophotothermal therapy, cancerous cells

\section{Introduction}

Smart nanocarriers with controlled drug delivery have been actively developed for overcoming typical limitations of conventional free drugs, such as lack of selectivity, non-specific targeting, poor solubility, limited stability, and rapid release. ${ }^{1,2}$
Correspondence: Sang-Wha Lee; Seong Soo A An

Gachon University, San 65, BokjeongDong, Sujeong-Gu, Seongnam 46I-70I, South Korea

Email Iswha@gachon.ac.kr;

seongaan@gachon.ac.kr
International Journal of Nanomedicine 2020:15 7667-7685

7667

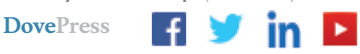

http://doi.org/10.2147/IJN.S254344 
Multifunctional mesoporous nanocarriers are normally constructed for controlled drug release in response to internal or external triggers such as polydopamine (PDA), ${ }^{3,4}$ graphene oxide (GO), ${ }^{5,6}$ and hydrogel matrix. ${ }^{7,8}$ However, the construction of internal trigger release systems, which are responding to subtle change in the surroundings, encountered significant challenges in cancer and inflammation processes, because of arbitrary $\mathrm{pH}$ changes during their evolution. ${ }^{9}$ Therefore, externally triggered release systems controlled by NIR irradiation, external $\mathrm{pH}$ changes, and electromagnetic field effects are intensively investigated. $1,10,11$

In recent years, mesoporous silica nanoparticles (MSNs) have been actively employed as smart nanocarriers for anticancer therapeutics due to its easy functionalization, large surface area for high drug loading, specific targeting cancer therapy, and bio-imaging agent. ${ }^{12-14}$ Furthermore, inorganic nanocrystals ( $\mathrm{Au}, \mathrm{Ag}, \mathrm{Fe}_{3} \mathrm{O}_{4}$, $\mathrm{MnO}, \mathrm{CuS}$ ) are integrated with $\mathrm{MSNs}$ to create a multifunctional core-shell type of MSNs-based drug delivery system. $^{15}$ Among them, gold and magnetic NPs are becoming important ingredients in the core-shell MSNs, because of their optical uniqueness and magnetic features in biomedical applications. These core-shell type MSNs can be promising theranostic nanocarriers with high loading capability, cell targeting specificity, and bio-imaging agents, as well as by adding stimuli-responsive drug release and hyperthermia treatment. ${ }^{16-20}$

Graphene oxide (GO) possesses advantageous biocompatibility, large specific surface area, and $\pi$-conjugated nanostructures which can confer excellent water solubility, physiological stability, and capacity for drug delivery. ${ }^{21,22}$ Likewise, polydopamine (PDA) possess good biocompatibility, unique chemical structure, and photothermal heating effects, which can be rapidly integrated into the construction of tumor-targeted drug delivery systems. ${ }^{23}$ In the meanwhile, plasmonic gold can absorb the nearinfrared radiation (NIR) and convert it to thermal energy because of intense surface plasmon resonance (SPR) and low quantum yield. ${ }^{24,25}$ It is highly expected that plasmonic gold combined with PDA or GO nanosheets can produce synergistic photothermal heating effects on the cancer cell treatment. ${ }^{26-28}$ Additionally, the combination of hyperthermia and chemotherapy in one unit would be very effective in killing multiple cancer cells. ${ }^{29-31}$

In the case of nanocarriers without targeting moieties, tumor accumulation is dependent upon direct injection, selective tumor embolization, or passive targeting.
Therefore, non-targeting nanocarriers usually cause harmful impacts of released drugs during the process of cancer therapy, such as side effects on the nearby cells (or tissues) and low accumulation of drugs in the lesion treatment. ${ }^{32,33}$ In this regard, core-shell type magnetic MSNs can be fully exploited as a promising targeted-delivery vehicle, wherein drugs are delivered to the specific location in vivo under an external magnetic field. ${ }^{34}$ A more advanced platform based on core-shell type MSNs can be actively targeted to cancer cells by surface functionalization with natural ligands for cell surface receptors, nucleic acids, peptides, non-immunoglobulin scaffolds, or antibodies. ${ }^{35}$ Among them, antibodies can play a vital role in modern cancer therapeutics as a specific targeting agent for cancer cells without significant side-effects and adequate plasma half-life. $^{36}$

The aim of the current work is to overcome the limitations of conventional drug delivery systems, eg, poor solubility, limited stability, rapid metabolization of the drug, undesired side-effects, and lack of selectivity toward specific cells types. ${ }^{37,38}$ The core-shell type mesoporous MSNs were prepared by embedding a $\mathrm{Fe}_{3} \mathrm{O}_{4}$ core in a mesoporous silica shell, followed by grafting with fluorescent conjugates, and coating with a PDA/GO double layer, hereafter referred to as FS3-based NPs (or nanocarriers). Our FS3-based NPs combined multimodal functions onto one single unit, such as mesoporosity, for high drug loading, stimuli-responsive drug delivery, fluorescent bioimaging, magnetic separation, photothermal heating effect, and specific antibody targeting. Notably, GO-coated FS3 exhibited high sensitivity in the dual stimuli ( $\mathrm{pH}, \mathrm{NIR})$ responsive release behavior, whereas Au Nps-deposited FS3 highlighted strong NIR absorption, enabling photothermal destruction of HeLa cells under NIR irradiation (808 nm, $1.5 \mathrm{~W} / \mathrm{cm}^{2}, 5-10$ minutes). Finally, the biocompatibility, cellular uptake, cytotoxicity, and photothermal therapy on these FS3-based nanocarriers were systematically investigated for improved treatment of cancer cells.

\section{Experimental Sections}

\section{Chemicals}

$\mathrm{FeCl}_{3} \cdot 6 \mathrm{H}_{2} \mathrm{O}$ (98.0-102\%), $\mathrm{FeCl}_{2} \cdot 4 \mathrm{H}_{2} \mathrm{O}$ (99.99\%), $\mathrm{NaOH}$ ( $\geq 98 \%$ ), tetraethyl orthosilicate (TEOS, 99\%), cetyltrimethylammonium bromide (CTAB, 99\%), $\mathrm{NH}_{4} \mathrm{~F}$ (99.99\%), dopamine hydrochloride (powders), 3-aminopropyltrimethoxy-silane (APTMS, 97\%), fluorescein isothiocyanate (FITC, 90\%), chloroform ( $\geq 99.5 \%$ ), cisplatin 
(pharmaceutical secondary standard), dimethyl sulfoxide (DMSO, $\geq 99.9 \%$ ), tris(hydroxymethyl)aminomethane (Tris, $\geq 99.8 \%$ ), graphene oxide (GO, $4 \mathrm{mg} / \mathrm{mL}$ ), 3,4-dihydroxyhydrocinnamic acid (hydrocaffeic acid, 98\%), $\mathrm{HAuCl}_{4} \quad$ (99.999\%), 2-(N-morpholino) ethanesulfonic acid hydrate (MES, $\geq 99.5 \%$ ), $N$-(3-dimethylaminopropyl)- $N$ '-ethylcarbodiimide hydrochloride (EDC, crystalline), and $N$-hydroxysuccinimide (NHS, 98\%) were purchased from Sigma-Aldrich (South Korea). Phosphate-buffered saline (PBS) was purchased from Bioneer (South Korea). A monoclonal anti-human epidermal growth factor receptor (EGFR) antibody, clone AT6E3 (EGFRab), was obtained from ATGen, Inc. Ethanol and water (high-performance liquid chromatography (HPLC) grade) were used as without further purification treatment. Glassware was cleaned by an aqua regia solution of $\mathrm{HNO}_{3}: \mathrm{HCl}=1: 3$ and then washed with deionized (DI) water more than three times.

\section{Synthesis of Magnetic NPs $\left(\mathrm{Fe}_{3} \mathrm{O}_{4}\right)$}

$\mathrm{Fe}_{3} \mathrm{O}_{4}$ magnetic NPs were synthesized using co-precipitation of ferric and ferrous salts under atmospheric pressure (760 mm of $\mathrm{Hg}$ ). Both $\mathrm{FeCl}_{3} \cdot 6 \mathrm{H}_{2} \mathrm{O}\left(7.5 \mathrm{~g}\right.$ ) and $\mathrm{FeCl}_{2} \cdot 4 \mathrm{H}_{2} \mathrm{O}$ (3 g) were added into $160 \mathrm{~mL}$ of deoxygenated water by purging inert $\mathrm{N}_{2}$ gas. The solution was stirred for 60 minutes at constant temperature of $30^{\circ} \mathrm{C}$. The chemical precipitation occurred at $30^{\circ} \mathrm{C}$ under vigorous stirring by injecting $40 \mathrm{~mL}$ of $\mathrm{NaOH}(2.0 \mathrm{M})$ slowly under the steady continuous purging with $\mathrm{N}_{2}$ gas. Even after the color changed from yellow to black, the solution was continuously stirred at $70^{\circ} \mathrm{C}$ for 6 hours. The solution reduced to room temperature $\left(25-26^{\circ} \mathrm{C}, \mathrm{RT}\right)$, and the precipitates were separated using a permanent magnet bar and washed with deoxygenated DI water to neutral $\mathrm{pH}$. Finally, $\mathrm{Fe}_{3} \mathrm{O}_{4}$ was washed with acetone and dried in the freeze-dryer system. $^{39}$

\section{Synthesis of FS3}

The synthesis procedures of conjugating fluorescein isothiocyanate (FITC) onto MSF were conducted under dark conditions, due to the light-sensitive property. FITC (3 mg) was mixed with 3-aminopropyltrimethoxysilane (APTMS, $140 \mu \mathrm{L}$ ) in $4 \mathrm{~mL}$ of ethanol for 6 hours in the dark. The resultant APTMS-FITC complex solution was stored at approximately $10^{\circ} \mathrm{C} . \mathrm{Fe}_{3} \mathrm{O}_{4}$ nanocrystals $(20 \mathrm{mg}$, ca. $15 \mathrm{~nm})$ were dispersed in chloroform $(2 \mathrm{~mL})$. The $\mathrm{Fe}_{3} \mathrm{O}_{4}$ solution was poured into CTAB $(7.5 \mathrm{~mL}, 0.16 \mathrm{M})$. The mixed solution was stirred vigorously for 1 hour, leading to an oil-in-water microemulsion brow milk solution. The mixture was heated up to $60^{\circ} \mathrm{C}$ and aged at the same temperature for 20 minutes to evaporate chloroform, forming a transparent black solution of $\mathrm{Fe} 3 \mathrm{O} 4 / \mathrm{CTAB}{ }^{40,41}$

$\mathrm{NH}_{4} \mathrm{~F}(0.4 \mathrm{~g})$ and water $(70 \mathrm{~mL})$ were heated to $70^{\circ} \mathrm{C}$ for 40 minutes to reach approximately $\mathrm{pH} 10$, followed by the addition of $\mathrm{Fe}_{3} \mathrm{O}_{4} / \mathrm{CTAB}$ solution under constant stirring at $70^{\circ} \mathrm{C}$ for 30 minutes. After slowly adding TEOS (1 $\mathrm{mL}$ ) into the mixed solution by droplet injection, a whitebrown sol-gel solution was formed under vigorous stirring for 5 minutes. The APTMS-FITC complex was slowly added into the sol-gel solution. The synthetic procedure was carried out in the dark with reflux at $70^{\circ} \mathrm{C}$ for 12 hours. The products were centrifuged and washed with copious DI water and ethanol (thrice) to remove unreacted components. To extract the remaining CTAB, the isolated product was dispersed in ethanol $(200 \mathrm{~mL})$ and kept stirred under reflux at $70^{\circ} \mathrm{C}$ for 5 hours. The final product was centrifuged, washed with water, dried in a freeze dryer for 72 hours, and stored in the dark prior to the further characterization. $^{41,42}$ To compare with FS3, only silica complex (S3) without $\mathrm{Fe}_{3} \mathrm{O}_{4}$ was synthesized by the same method. In addition, MSNs was also synthesized by the same method without grafting the APTMS-FITC complex.

\section{Cisplatin Loading into FS3}

Cisplatin was weakly acidic due to its monohydrated form at neutral $\mathrm{pH}^{43}$ Cisplatin solubility was at $2.5 \mathrm{mg} / \mathrm{mL}$ and $4 \mathrm{mg} / \mathrm{mL}$ in water at $25^{\circ} \mathrm{C}$ and $35^{\circ} \mathrm{C}$, respectively. However, the solubility of cisplatin in DMSO was notably high $\left(25 \mathrm{mg} / \mathrm{mL}\right.$ at $25^{\circ} \mathrm{C}$. Due to the light susceptibility (or sensitivity) of cisplatin, all synthetic steps were conducted in the dark.

For loading cisplatin drug into mesoporous nanoparticles (NPs), FS3 (150 mg) was dispersed in DMSO (5 mL), until the concentration of cisplatin reached $0.033 \mathrm{M}$. The solution was continuously stirred for 24 hours at $25-26^{\circ} \mathrm{C}$ (RT) to load the maximal amounts of cisplatin. Cisplatinloaded FS3 (FS3/C) was separated by centrifugation. In order to determine the loading amount of cisplatin, the supernatant was collected to calculate the difference between the initial amount of cisplatin and final remaining values in supernatant. ${ }^{44}$

\section{PDA and GO Coating (FS3P-G)}

To coat polydopamine (PDA) layer over the FS3-drug system, FS3/C (100 mg) was dispersed in Tris- $\mathrm{HCl}$ buffer 
(10 $\mathrm{mL}$ of $10 \mathrm{mM}$ at $\mathrm{pH} 8.5$ ), followed by adding dopamine hydrochloride $(10 \mathrm{mg})$. The polymerization reaction of dopamine was carried out for 3 hours under continuous stirring in the dark. The PDA-coated FS3/C (FS3P/C) was centrifuged for 5 minutes and washed with DI water to remove unpolymerized residues. The PDA-coated FS3/C (FS3P/C) was stored at $4{ }^{\circ} \mathrm{C}$ prior to the release test. ${ }^{43}$ To prepare a GO-coated FS3-drug system, FS3P/C $(50 \mathrm{mg})$ was dispersed in GO solution $(2 \mathrm{~mL})$. The mixed solution was stirred at RT for 2 hours to complete the GO wrapping process. The GO-coated FS3 (FS3P-G/C) was collected by centrifugation at $6,000 \mathrm{rpm}$ and thoroughly washed with DI water to remove any residue. ${ }^{45}$

\section{Gold Deposition (FS3P-A/C)}

Catechol moieties were conjugated onto the FS3P/C using 1-(3-dimethylaminopropyl)-3-ethylcarbodiimide (EDC) coupling reaction. Shortly, hydrocaffeic acid (5 mg in 1.5 $\mathrm{mL}$ of PBS solution at $\mathrm{pH} 5.0$ ) was added into the $\mathrm{FS} 3 \mathrm{P} / \mathrm{C}$ solution (50 mg in $3 \mathrm{~mL}$ of PBS solution) containing EDC $(8 \mathrm{mg})$. The reaction was carried out at $\mathrm{pH} 5.0$ for 2 hours. The resulting FS3P/C-Catechol was isolated by centrifugation. To deposit gold NPs onto the FS3-drug system, FS3P/C-Catechol $(50 \mathrm{mg})$ was added into $\mathrm{HAuCl}_{4}$ solution $(6 \mathrm{~mL}$ of $0.5 \mathrm{mM})$, and the deposition reaction was continued for 2 hours at $25-26^{\circ} \mathrm{C}$ (RT) under continuous stirring. The product was collected by centrifugation $(4500$ $\mathrm{x} g, 5$ minutes), and washed with DI water for a further utilization.

\section{EGFR Antibody Conjugation (FS3P-G-E/C)}

To conjugate antibodies onto the GO surfaces, EGFR antibody $(10 \mu \mathrm{g})$ was dispersed in MES buffer $(100 \mu \mathrm{L}, \mathrm{pH} 6)$. EDC $(25 \mu \mathrm{L}$ at $1 \mu \mathrm{L} / \mathrm{mL})$ was annexed to actuate the carboxylic acid groups of EGFR antibody. This solution was quickly added to the particle $(50 \mu \mathrm{g})$ in MES buffer (200 $\mu \mathrm{L}$ ). NHS (30 $\mu \mathrm{L}$ of $1 \mathrm{mg} / \mathrm{mL}$ in MES) was added to the suspension. The suspension was dispersed using an orbital shaker machine for 5 hours and washed with DI water. The product was dried in a freeze-dryer system and stored at $4^{\circ} \mathrm{C}$.

\section{Determination of Encapsulation Efficiency (EE) and Loading Capacity (LC)}

The EE and LC of cisplatin-loaded FS3 were determined by quantifying the absorption of the clear supernatant using UV-vis spectroscopy (NanoDrop, NanoDrop
Technologies, Wilmington, DE, USA). The corresponding calibration curve was obtained by testing the supernatant of cisplatin. Tests were performed in triplicate for each sample. The absorbance value of cisplatin was measured using UV-vis spectroscopy in DMSO and PBS buffer at the wavelength of $310 \mathrm{~nm}$ and $301 \mathrm{~nm}$, respectively.

The percentage of encapsulation efficiency and loading capacity of cisplatin in FS3, FS3P, FS3P-G, and FS3P-A were determined by the following equations, ${ }^{46}$ respectively: $E E=\left(A_{t}-A_{f}\right) / A_{t} \times 100 \%, L C=\left(A_{t}-A_{f}\right) /$ $W_{n} \times 100 \%$. Here, $\mathrm{A}_{\mathrm{t}}$ is the total amount of cisplatin, $\mathrm{A}_{\mathrm{f}}$ was the amount of free cisplatin in the supernatant after centrifugation, and $\mathrm{W}_{\mathrm{n}}$ is the weight of FS3 system for drug release. All measurements were made in triplicate, and the average value was reported.

\section{In vitro Drug Release Test of As-prepared Samples}

The in vitro drug release tests were carried out as follows: $50 \mathrm{mg}$ of each sample was dispersed in a definite volume $(5 \mathrm{~mL})$ of PBS at $\mathrm{pH} 7.4$ at $37^{\circ} \mathrm{C}$. The resulting suspension was placed in an incubator and stirred at $600 \mathrm{rpm}$ for a definite period, and a 4- $\mu \mathrm{L}$ aliquot was taken out of the dissolution medium at appropriate time intervals. The concentration of released drug was measured using UV-vis spectroscopy (NanoDrop, USA) at $301 \mathrm{~nm}^{46}$

\section{Cellular Uptake and Intracellular Distribution}

The HeLa cells were obtained from the American Type Culture Collection (ATCC CCL-2) and were grown in full medium to a final density of a $1 \times 10^{5}$ cells/well in 6 -well plates with the presence of a glass coverslips. On the next day, the cells were treated with as-prepared NPs (SP/C, FS3P-G/C, FS3P-A/C, and FS3P-G-E/C) at $5 \mu \mathrm{g} / \mathrm{mL}$ for 4 hours. Cells were further washed with PBS three times and fixed with $4 \%$ paraformaldehyde in PBS for 10 minutes at RT. Cells on the slides were stained with 4,6 diamidino-2phenylindole (DAPI, $1 \mu \mathrm{g} / \mathrm{mL}$ ) in PBS for 20 minutes at RT to stain the nucleus cells after washing three times with PBS. The cells in each slide were mounted using the Eukitt ${ }^{\circledR}$ Quick-hardening mounting medium (SigmaAldrich) for observation under confocal microscopy. Lastly, the mounted cells were imaged at $\lambda=408$ and $488 \mathrm{~nm}$ for detecting fluorescence intensity of DAPI and FITC by confocal microscopy (Nikon TE2000-E Eclipse C1si), respectively. 
The distribution of FMAF-based NPs in cells was also tested by flow cytometry analysis. HeLa cells were seeded on a 6 -well plate and cultured at $37^{\circ} \mathrm{C}$ under $5 \% \mathrm{CO}_{2}$ on the day before. Then, the cells were treated with as-prepared NPs at $5 \mu \mathrm{g} / \mathrm{mL}$. Following 4 hours and 24 hours coincubation, cells were rinsed with PBS and collected by trypsinization. The cells were collected by centrifugation, and $1 \times$ PBS $(500 \mu \mathrm{L})$ was added to re-suspend the cells for flow cytometry (LSRII, BD Biosciences). The FICT fluorescence of the four NPs was tested with approximately 10,000 gated cells. The normal cells without any fluorescence labeling were used. The FlowJo software was used to analyses flow cytometry data.

Furthermore, to visualize NP distributions within cells, the four different samples were added to SH-SY5Y cells cultured in $75-\mathrm{cm}^{2}$ flasks at $5 \mu \mathrm{g} / \mathrm{mL}$ for 4 hours. Cells were rinsed with PBS (three times). Cells were scraped off the flask and centrifuged into a pellet. The pellet was set in resin, and micron-sized slices were cut. After drying the samples, transmission electron microscopy (TEM) was taken using a Hitachi H-7600 (Japan) microscope operated at $80 \mathrm{kV}$ and a Tecnai G2 F30 (Germany) microscope operated at $300 \mathrm{kV}$.

\section{Cytotoxicity Study}

The HeLa, neuroblastoma (SH-SY5Y ATCC CRL 2266), and embryonic kidney (HEK293 ATCC CRL-1573) cell lines were cultured in a 96-well plate with a cell density of $2 \times 10^{4}$ cells per well. The day after, old medium was replaced with fresh medium containing different NP samples (S, S3, SP/C, FS3P-G/C, FS3P-A/C, and FS3P-G-E/ C) at various concentrations $(10,5,2.5,1.25$, and 0.625 $\mu \mathrm{g} / \mathrm{mL}$ ). After another incubation of 48 hours, old medium was removed, followed by washing with PBS three times, and fresh medium $(100 \mu \mathrm{L})$ was added into each well. After another 30 minutes incubation to equilibrate to RT, $100 \mu \mathrm{L}$ of CellTiter-Glo ${ }^{\circledR}$ Luminescent reagent (Promega) was added to each well to measure cell viability. ${ }^{47}$ After gently shaking for 10 minutes at RT, the luminescence signal was measured using a microplate reader (Perkin Elmer, Victor X5, USA). The percentage of cell viability was calculated based on luminescence absorbance changes by comparing absorbance values between test and control wells without any treatment. The experiments were repeated three times for statistical analysis.

In addition, FS3P-G/C and FS3P-A/C were further evaluated for efficacy of photothermal therapy in HeLa cells. Then $2 \times 10^{4}$ cells/well were grown on 96 -well plates and incubated for 24 hours at $37^{\circ} \mathrm{C}$ with the samples at 5 $\mu \mathrm{g} / \mathrm{mL}$. After 4 hours of incubation, the cells were irradiated for 5,10 , or 15 minutes with or without $808 \mathrm{~nm}$ NIR laser at $1.5 \mathrm{~W} / \mathrm{cm}^{2}$. The cell viability was measured using CellTiter-Glo ${ }^{\circledR}$ Luminescent after 48 hours incubation. To further evaluate the morphology of cells, a JuLITM Stage Real-Time Cell History Recorder (NanoEntek, Korea) was used during the experiment.

\section{Results and Discussion}

\section{Synthesis and Characterization of Multifunctional Mesoporous NPs Synthetic Scheme of FS3-Based NPs}

The objective of the present investigation was to synthesize core-shell $\mathrm{Fe}_{3} \mathrm{O}_{4}$-mesoporous silica NPs coated with PDA layer and Au NPs. According to the preparation strategy presented in Scheme 1, the initial step was to synthesize superparamagnetic NPs. The following step was to prepare the core-shell $\mathrm{Fe}_{3} \mathrm{O}_{4}$-mesoporous NPs grafted with APTMS-FITC fluorescent complex, hereafter referred to as FS3. The core-shell FS3 NPs were coated with biocompatible PDA with multiple amine groups. The PDA-coated FS3 (FS3P) NPs exhibited the highly positive zeta-potentials in aqueous solution $(+21.1 \mathrm{mv})$ from the negative value of FS3 $(-19.1 \mathrm{mv})$, and the hydrodynamic size of the NPs was approximately $100 \mathrm{~nm}$ by DLS instrument at the Smart Materials Research Center for IoT at Gachon University. The size of FS3P was smaller than that of the vascular leakage in tumor sites for their passage into the tumor, but larger than that of normal vascular pores. Furthermore, the combination of APTMS-FITC complex and PDA layer played as a gatekeeper, which produced a pore closure effect, resulting in sustained releases of small drug molecules through the porous channels of FS3-based NPs. After attaching hydrocaffeic acid onto the surface of FS3P through electrostatic interaction and hydrogen bonding between carboxylate groups of hydrocaffeic acid and amine groups of PDA, the catechol-enriched PDA surface acted as a highly reductive reservoir for the seed formation of $\mathrm{Au}$ and continuous growth into gold NPs. ${ }^{48}$ In addition, cross-linking reactions between oxidized quinones and amine groups of PDA produced additional anchoring gold NPs on the surface of FS3P through catechol-gold interactions. ${ }^{49,50}$ Notably, GO-wrapped FS3P/C (FS3P-G/ C) improved the drug delivery performance through the consolidated double layer consisting of GO nanosheets and PDA layer, improving the absorption of FS3P into 


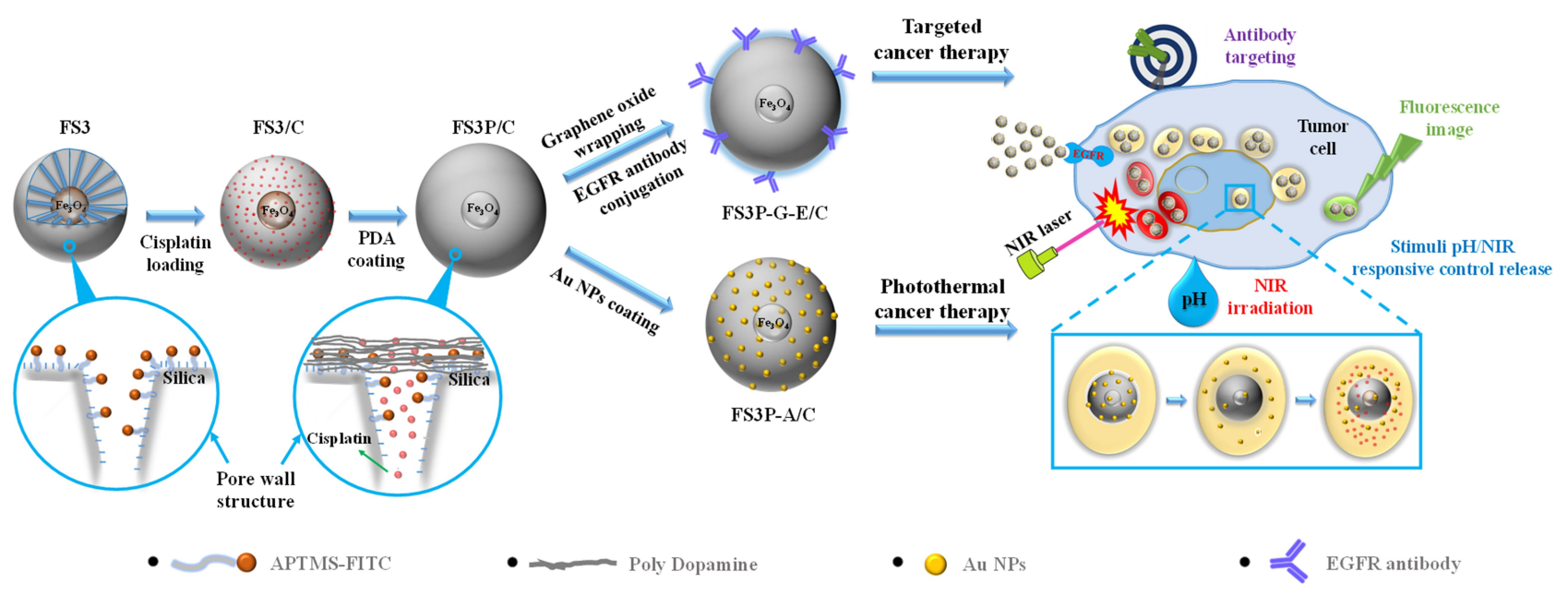

Abbreviations: $\quad 3=3$-AminoPropylTriMethoxySilane-Fluorescein Iso ThioCyanate (APTMS-FITC);

$\mathrm{F}=\mathrm{Fe}_{3} \mathrm{O}_{4} \mathrm{NPs} ; \mathrm{S}=$ Silica nanoparticles (MSNs); $\mathrm{P}=$ Polydopamine (PDA);

$\mathrm{G}=$ Graphene oxide; $\mathrm{A}=\mathrm{Au}$ NPs; $\mathrm{E}=\mathrm{EGFR}$ antibody $; \mathrm{C}=$ Cisplatin

Scheme I Schematic illustration of core-shell FS3, double layer coating by PDA and Au coating (FS3P-A/C), Graphene oxide wrapping and EGFR antibody conjugating (FS3P-G-E/C); mechanism of stimuli pH/NIR responsive controlled release; and biomedical application through $\mathrm{Au} / \mathrm{Fe}_{3} \mathrm{O}_{4} / \mathrm{PDA}_{\mathrm{Photothermal}}$ therapy, the magnetically guided and EGFR antibody target.

cells. $^{51}$ More detailed descriptions about APTMS-FITC complex, polydopamine (PDA) layer, and electrostatic interactions between PDA and graphene oxide are provided in Supplementary Figure S1. Whole abbreviations of as-prepared FS3-based NPs are also listed in the bottom part of Scheme 1.

\section{Porosity and Pore Structures - X-Ray Diffraction - Magnetic Property Analysis of FS3-Based NPs}

The Brunauer-Emmett-Teller (BET) surface area and pore structures of as-prepared samples (S, S3, and FS3) were analyzed by $\mathrm{N}_{2}$ adsorption-desorption isotherm measurements. Then, S3 was the abbreviated word for MSNs grafted with APTMS-FITC complex. Figure 1A-1 shows the nitrogen adsorptions of S, S3, and FS3, displaying typical type II isotherms with two steps indicating the presence of mesoporous structures according to the International Union of Pure and Applied Chemistry (IUPAC) classification. A pore-filling adsorption isotherm was sharp in the relative pressure of $0.85-1.0 \mathrm{~atm}$, confirming the narrow pore size distribution. The hysteresis loop observed around 0.9 atm was attributed to the inter-particle porosity, which was usually observed in mesoporous NPs system. ${ }^{16-18}$ Compared to that of MSNs, the adsorbed nitrogen amount of S3 significantly increased, but the shape of the hysteresis remained unchanged. The BET surface area and pore volume of MSN were $260 \mathrm{~m}^{2} / \mathrm{g}$ and
$0.62 \mathrm{~cm}^{3} / \mathrm{g}$, respectively. After grafting with APTMSFITC complex, the BET surface area and pore volume of $\mathrm{S} 3$ significantly increased to $1,156 \mathrm{~m}^{2} / \mathrm{g}$ and $1.67 \mathrm{~cm}^{3} / \mathrm{g}$, respectively (Supplementary Table S1). However, an average pore diameter decreased from $2.38 \mathrm{~nm}$ to 1.45 $\mathrm{nm}$, and pore size reduced to nearly half from $10.2 \mathrm{~nm}$ to $5.6 \mathrm{~nm}$ (as summarized in Supplementary Table S1). These data indicate the grafting of the APTMS-FITC complex onto the pore walls of MSNs. After performing concurrent synthesis of core-shell $\mathrm{Fe}_{3} \mathrm{O}_{4}$-incorporated S3 (so-called FS3), the BET surface area and pore volume of FS3 were reduced to $846 \mathrm{~m}^{2} / \mathrm{g}$ and $1.30 \mathrm{~cm}^{3} / \mathrm{g}$ from the initial values of $1,156 \mathrm{~m}^{2} / \mathrm{g}$ and $1.67 \mathrm{~cm}^{3} / \mathrm{g}$, respectively. On the contrary, average pore diameter slightly increased from $1.45 \mathrm{~nm}$ to $1.54 \mathrm{~nm}$, as shown in Figure 1A-2. These results suggested that the incorporation of $\mathrm{Fe}_{3} \mathrm{O}_{4}$ NPs within the mesoporous silica matrix did not change the pore structure of the FS3 significantly. The APTMS-FITC complex were uniformly distributed on the interior pore walls and the exterior silica surface (as depicted in Scheme 1), which were beneficial for loading large amounts of drug molecules. After PDA was coated over the FS3 NPs, the BET surface area of PDA-coated FS3 (FS3P) significantly reduced from 846 to $16 \mathrm{~m}^{2} / \mathrm{g}$. On the contrary, pore size increased dramatically from $6.2 \mathrm{~nm}$ to $23.1 \mathrm{~nm}$, indicative of large void space generated by 

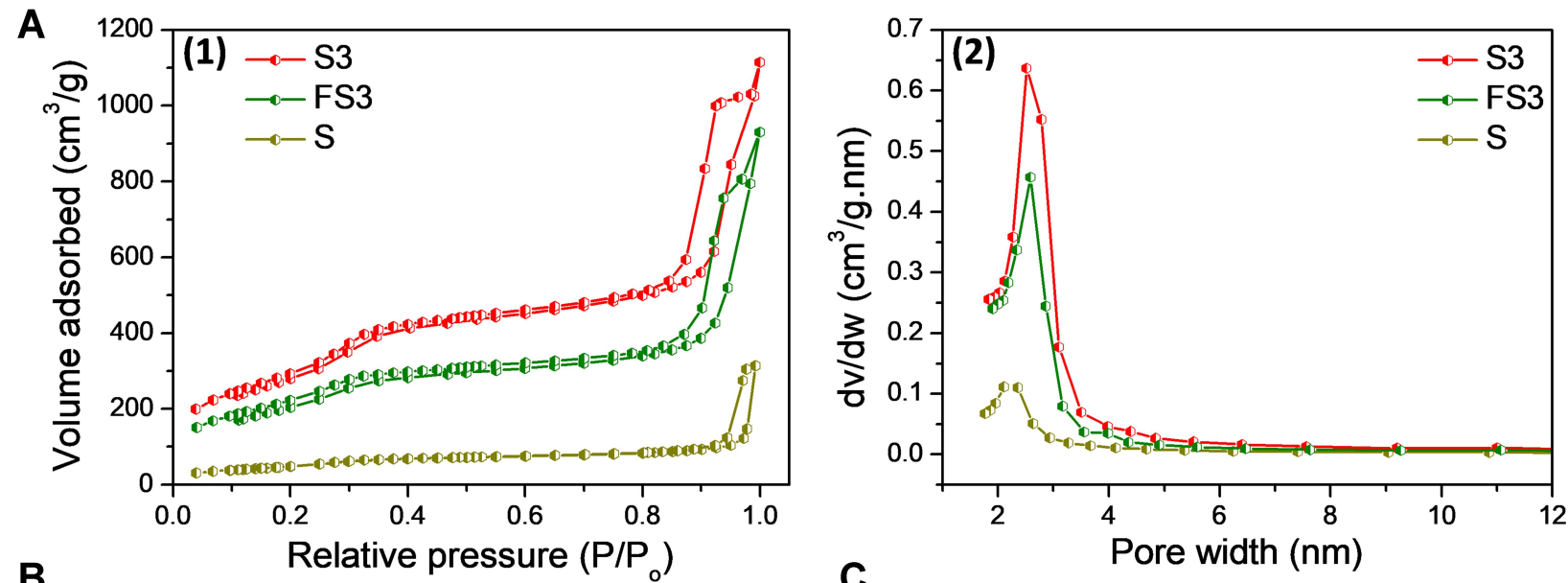

B
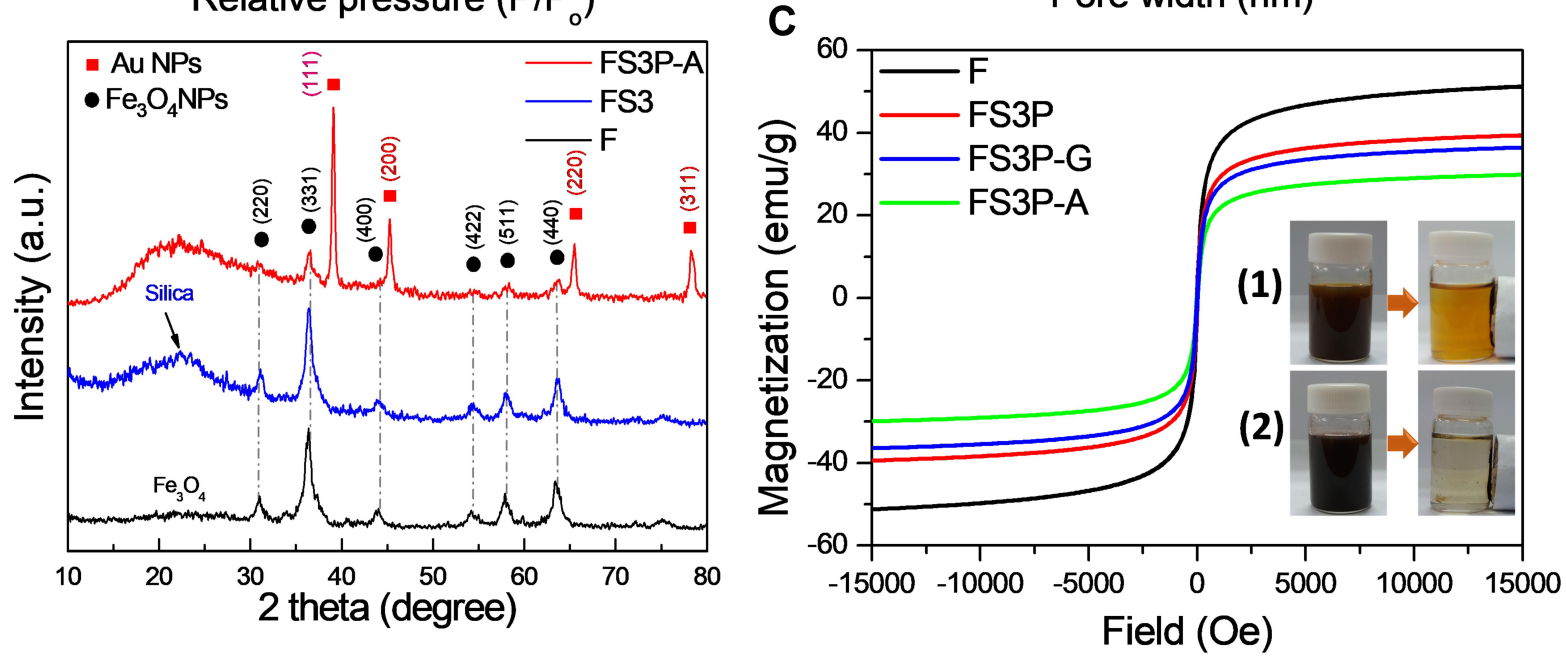

Figure I (A) Nitrogen adsorption/desorption isotherms (I) and pore size distribution (2) by the Barrett-Joyner-Halenda (BJH) analysis of S, S3, and FS3. (B) X-Ray Diffraction (XRD) intensity measurements of F, FS3, and FS3P-A. (C) Magnetic hysteresis loops of F, FS3P, FS3P-G, and FS3P-A; photographs of (I) Fe 3 O ${ }_{4}$ NPs and (2) FS3P-A NPs before and after separation with an external magnetic field.

PDA coating process. These data finally indicated the full capsulation of mesoporous FS3 by PDA layer.

Powder X-ray powder diffraction (XRD) analysis confirmed the composition of the as-synthesized samples, as shown in Figure 1B. The powder diffraction pattern of the MSNs indicated a broad peak at $2 \theta=22.5^{\circ}$ that revealed the amorphous nature of the silica matrix (ie, the absence of ordered crystalline structure). ${ }^{51}$ The XRD pattern of $\mathrm{Fe}_{3} \mathrm{O}_{4}$ NPs was also compared with those of FS3 and FS3P-A NPs. The diffraction peaks of FS3 and FS3P-A matched well with those of $\mathrm{Fe}_{3} \mathrm{O}_{4} \mathrm{NPs}$, confirming the incorporation of iron oxide in all the samples. The diffraction signatures at two-theta values of $30.9^{\circ}, 36.4^{\circ}, 43.9^{\circ}, 54.2^{\circ}, 57.9^{\circ}$, and $63.5^{\circ}$ are corresponding to (220), (311), (400), (422), (511), and (440) planes for $\mathrm{Fe}_{3} \mathrm{O}_{4}$, respectively. After FS3P was anchored by gold NPs, FS3P-A exhibited an additional four peaks at $2 \theta$ values of $39.0^{\circ}, 45.3^{\circ}, 65.4^{\circ}$, and $78.4^{\circ}$, corresponding to (111), (200), (220), and (311) lattice planes of the face-centered cubic gold (space group FM3M, JCPDS File No. 89-3697), respectively.

Hysteresis loops of the magnetic NPs are shown in Figure $1 \mathrm{C}$. All the samples incorporated with $\mathrm{Fe}_{3} \mathrm{O}_{4} \mathrm{NPs}$ revealed a superparamagnetic behavior that was desirable for biomedical applications. ${ }^{51}$ Pure $\mathrm{Fe}_{3} \mathrm{O}_{4}$ exhibited a saturation magnetization at $51.2 \mathrm{emu} / \mathrm{g}$. This value was reduced to $39.4 \mathrm{emu} / \mathrm{g}$ when $\mathrm{Fe}_{3} \mathrm{O}_{4}$. NPs was encapsulated with mesoporous silica shell, and grafting with APTMSFITC complex and coating with polydopamine layer (FS3P). After wrapping by GO nanosheets, the magnetization of FS3P-G was slightly decreased to $36.4 \mathrm{emu} / \mathrm{g}$. The magnetization was further decreased to $29.8 \mathrm{emu} / \mathrm{g}$ when gold NPs covered the surface of the sample (FS3P-A). The decrease in the magnetization values was due to the increase of nonmagnetic materials. Nonetheless, magnetic NPs have several advantages in drug delivery systems: i) facile separation by a simple magnetic manipulation, ii) 

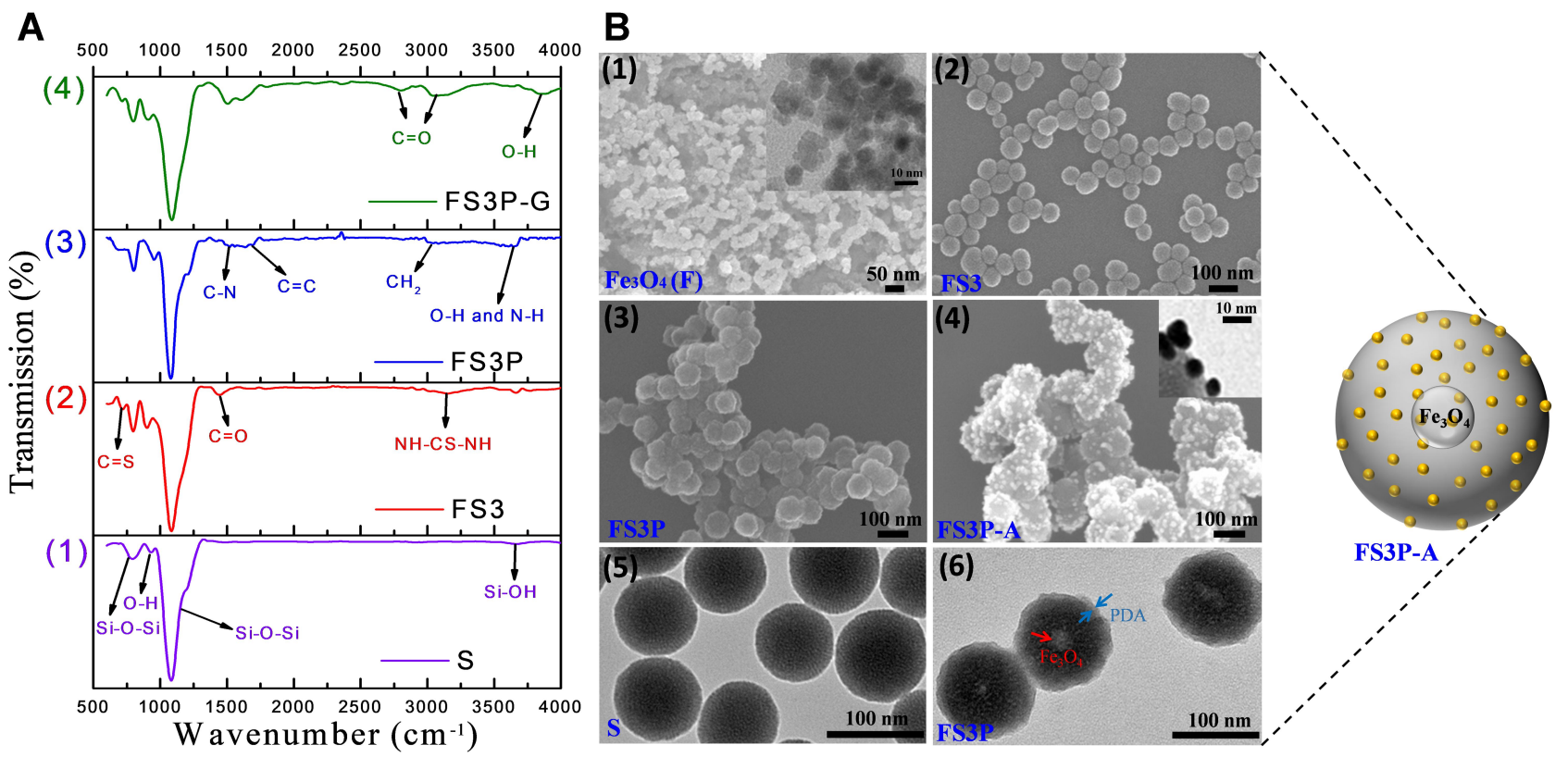

Figure 2 (A) FT-IR spectra of (I) S, (2) FS3, (3) FS3P, and (4) FS3P-G. (B) SEM image and inset TEM image of $\mathrm{Fe}_{3} \mathrm{O}_{4}$ (F) (I), SEM image of FS3 (2), SEM image of FS3P (3), SEM image and inset TEM image of FS3P-A (4); TEM images of S (5), and TEM images of FS3P (6).

magnetic-targeting capability, and iii) high NIR absorption and conversion into thermal energy. ${ }^{18,52}$

\section{FTIR Analysis - SEM and TEM Images}

FTIR spectrum was measured to characterize the surface modifications at each synthetic step. As shown in Figure 2A-1, the characteristic peaks corresponding to the antisymmetric and symmetric stretching vibrations of the Si-O-Si bond in oxygen-silica tetrahedron were clearly observed at 1,078 and $791 \mathrm{~cm}^{-1}$, respectively. The weak bands at 3,656 and $933 \mathrm{~cm}^{-1}$ were assigned to stretching vibrations of silanol groups and absorbed water, respectively. After grafting with APTMS-FITC complex, the FS3 showed new bands at 713 and $1,441 \mathrm{~cm}^{-1}$, corresponding to $\mathrm{C}-\mathrm{S}$ and $\mathrm{CO}$ vibrations, respectively. The peaks at 3,145 and $3,662 \mathrm{~cm}^{-1}$ were assigned as $\mathrm{NH}$ stretch and $\mathrm{NH}$ symmetric from NH-CS-NH groups originated from APTMS-FITC complex, respectively, indicating the successful grafting APTMS-FITC complex onto the pore walls (Figure 2A-2). After the PDA layer formed over the FS3 NPs, a broad band appeared at $\sim 3,660 \mathrm{~cm}^{-1}$ attributed to the stretching vibrations of $\mathrm{OH}$ and $\mathrm{NH}$ bonds in PDA. Additional peak also appeared at $\sim 3,014 \mathrm{~cm}^{-1}$, which was assigned as the $\mathrm{C}-\mathrm{H}$ asymmetric vibration of aliphatic $\mathrm{CH}_{2}$ in PDA. The peaks at 1,502 and $1,679 \mathrm{~cm}^{-1}$ also indicated the presence of $\mathrm{C}-\mathrm{N}$ and $\mathrm{C}=\mathrm{C}$ groups of the benzene ring (Figure 2A-3). After wrapping with GO nanosheets, the absorption band at $3,830 \mathrm{~cm}^{-1}$ was assigned to the $\mathrm{O}-\mathrm{H}$ stretching vibrations. The absorption peak at 2,796 and $3,025 \mathrm{~cm}^{-1}$ could be assigned as the $\mathrm{C}=\mathrm{O}$ stretching of carboxylic and/or carbonyl moiety functional groups (Figure 2A-4). All the FTIR spectra indicated the successful surface modifications of multifunctional FS3 during the consecutive fabrication steps, as described in Scheme 1.

According to the scanning electron microscope (SEM) and transmission electron microscopy (TEM) (inset) images in Figure 2B-1, the $\mathrm{Fe}_{3} \mathrm{O}_{4}$ NPs exhibited a spherical shape with a diameter range of 10-20 nm. After the concurrent sol-gel reaction and grafting of APTMS-FITC complex, the $\mathrm{Fe}_{3} \mathrm{O}_{4}$-incorporated S3 (FS3) NPs exhibited uniform orbicular shape with an average diameter of $\sim 90$ $\mathrm{nm}$ (Figure 2B-2). When the FS3 was coated with a thin PDA layer, the size of FS3P slightly increased by $\sim 10 \mathrm{~nm}$ (Figure 2B-3). As shown in Figure 2B-4, small gold NPs anchored on the surface of FS3P NPs. Supplementary Figure S2A reveals the UV-vis absorption spectra of FS3P-A which was prepared by $1.5 \mathrm{mM}$ of $1.0 \mathrm{wt} \%$ HAuCl4. ${ }^{53,54}$ The distinctly broader peak was observed at $\sim 700 \mathrm{~nm}$, due to the clustering effect of gold NPs. A SEM image of FS3P-G in Supplementary Figure S2B reveals the sheet-like wrapping of GO over the FS3P NPs. TEM images clearly depictthe two-dimensional pore arrangement of MSNs with perpendicular mesopores (Figure 2B-5). The TEM image of FS3P 
shows the yolk-shell structures, in which $\mathrm{S} 3$ shell uniformly coated onto the magnetic $\mathrm{Fe}_{3} \mathrm{O}_{4}$ cores. In addition, Figure 2B-6 displays the distinct coverage of PDA layer $(\sim 3 \mathrm{~nm})$ on the periphery of NPs. The chemical compositions were examined using scanning electron microscopyenergy dispersive spectroscopy (SEM-EDS). According to three major components ( $\mathrm{Au}, \mathrm{Si}$, and $\mathrm{Fe}$ ) shown in EDS spectra of Supplementary Figure S2C, core-shell type magnetic silica NPs were anchored with Au NPs, as previously shown in Figure 2B-4.

\section{In vitro Drug Release Under Stimuli $(\mathrm{pH}$, NIR) Operation}

\section{Photothermal Heating Effect by NIR Irradiation}

To study the photothermal heating effect on the FS3drug system, the temperature of FS3-drug solution was monitored under the irradiation of NIR light at $808 \mathrm{~nm}$ $\left(1.5 \mathrm{~W} / \mathrm{cm}^{2}\right)$ (Figure 3). As shown in Figure 3A, the temperature of MSNs solution increased slightly from $24.1^{\circ} \mathrm{C}$ to $29.2^{\circ} \mathrm{C}$ upon the NIR irradiation for 10 minutes. However, the temperature of $\mathrm{Fe}_{3} \mathrm{O}_{4}$ solution significantly increased from $24.6^{\circ} \mathrm{C}$ to $45.9^{\circ} \mathrm{C}$ under the same irradiation condition. After PDA/GO double layer coating, FS3P-G/C exhibited a significant increase in the solution temperature by $\sim 25^{\circ} \mathrm{C}$ (from $24.5^{\circ} \mathrm{C}$ to $49.0^{\circ} \mathrm{C}$ ). In contrast, $\mathrm{FS} 3 \mathrm{P}-\mathrm{G} / \mathrm{C}$ without $\mathrm{Fe}_{3} \mathrm{O}_{4}$ exhibited a lower increase in temperature by $\sim 15^{\circ} \mathrm{C}$ (from $24.7^{\circ} \mathrm{C}$ to $39.7^{\circ} \mathrm{C}$ ). Remarkably, goldcoated FS3 (FS3P-A/C) exhibited the maximal increase in the solution temperature, up to $59.1^{\circ} \mathrm{C}$, probably due the excellent heating effect of plasmonic gold NPs.
A
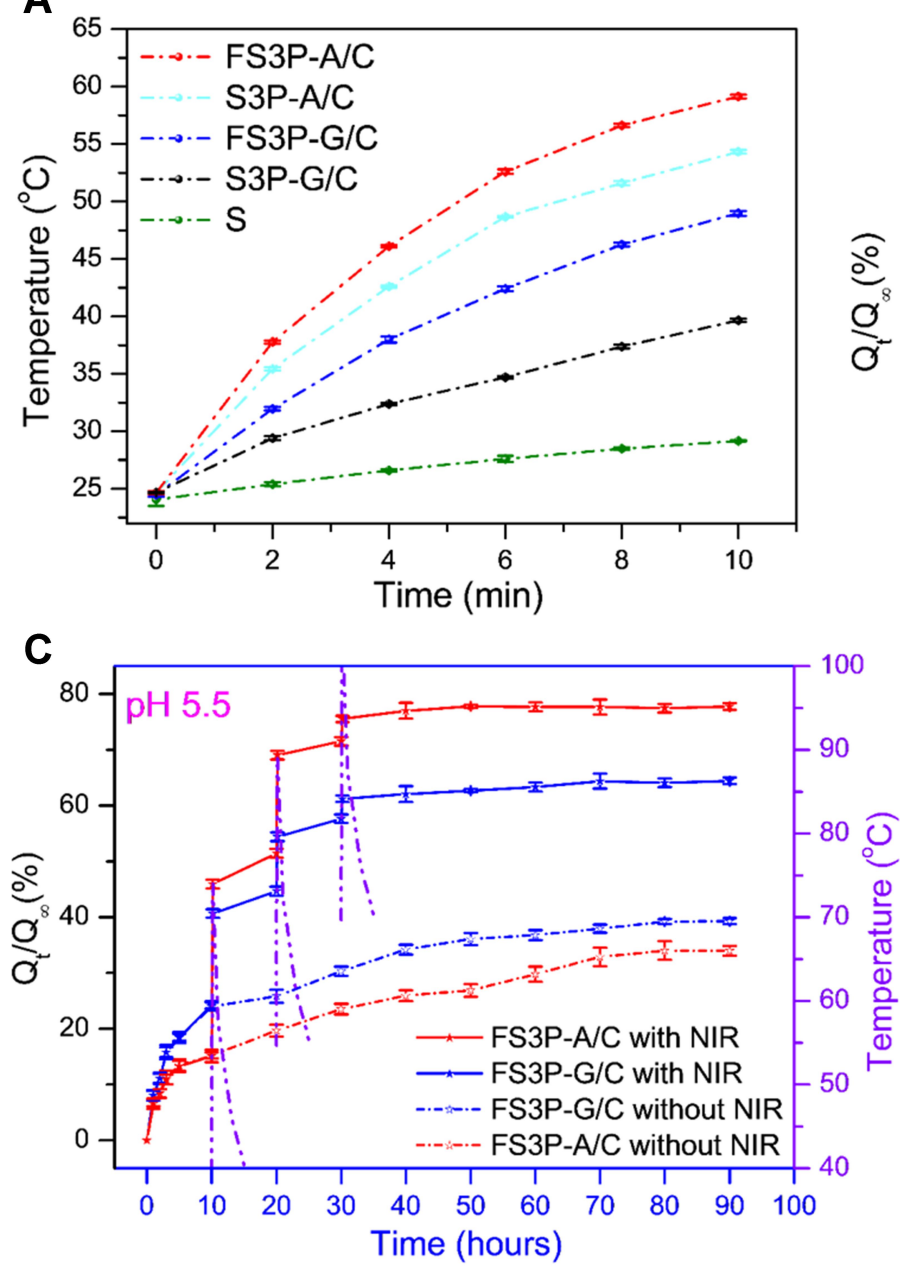

B

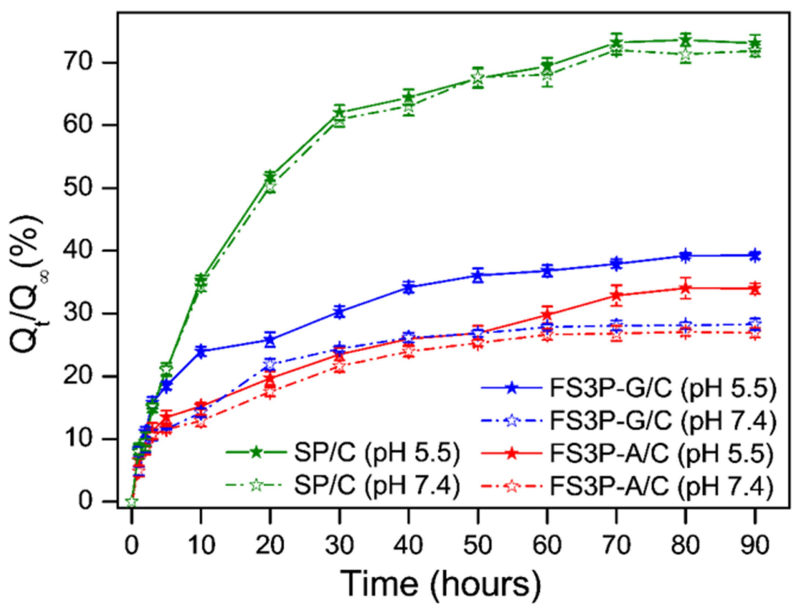

D

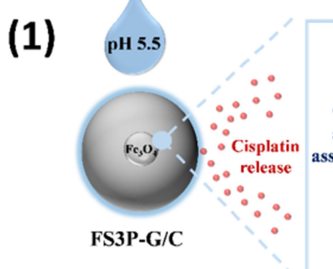

$\mathrm{pH}$ responsive control release

(2)

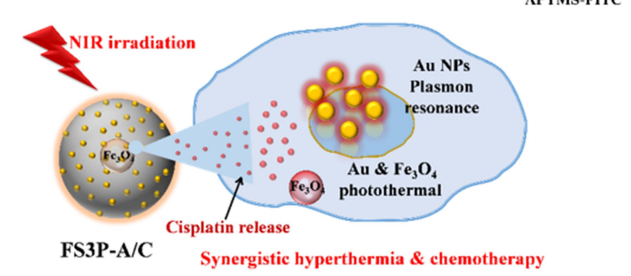

Figure 3 (A) Temperature-variation curves of S, S3P-G/C, FS3P-G/C, S3P-A/C, and FS3P-A/C, solutions during the exposure to an $808 \mathrm{~nm}$ laser at a power density of I.5 $\mathrm{W} / \mathrm{cm}^{2}$ for 10 minutes; (B) cisplatin release profiles from SP/C, FS3P-G/C, and FS3P-A/C in PBS at pH 7.4 and $\mathrm{pH} 5.5$; (C) cumulative cisplatin release from FS3P-G/C and FS3P-A/C in PBS at $\mathrm{pH} 5.5$ without and with NIR irradiation $\left(808 \mathrm{~nm}\right.$ laser, $\left.1.5 \mathrm{~W} / \mathrm{cm}^{2}\right)$ for 10 minutes; the dotted lines shown in $(\mathrm{C})$ indicate the temperature change of invitro solution induced by the irradiation of NIR light for 10 minutes; (D) mechanism of stimuli pH/NIR responsive controlled release from FS3P-G/C (I) and FS3P-A/C (2). 
Magnetic $\mathrm{Fe}_{3} \mathrm{O}_{4}$ can enhance the photothermal heating efficiency of the FS3-drug system upon NIR irradiation through polarized radiation in $\mathrm{Fe}_{3} \mathrm{O}_{4} .{ }^{55-57}$ As shown in Figure 3A, S3P-A/C NPs displayed high photothermal efficiency and quickly reached $54.3^{\circ} \mathrm{C}$, but the temperature rise was lower in comparison to that of FS3P-A/C (including $\mathrm{Fe}_{3} \mathrm{O}_{4}$ ). This result clearly indicates that a photothermal heating effect was additionally attributed to incorporated $\mathrm{Fe}_{3} \mathrm{O}_{4}$ upon NIR irradiation. In the case of FS3P-G/C, the PDA/GO double layers could have a synergy effect on the enhancement of photothermal conversion efficiency. PDA can obviously absorb the NIR light with a high photothermal efficiency and the photothermal heating effect was directly contributed by the degree of $\pi$ conjugations in GO. Even though GO was highly oxidized with disrupted $\pi$ conjugations, the chemical reduction of GO by PDA layer can restore the disrupted $\pi$ conjugations, consequently leading to the increase of NIR absorption. ${ }^{22,58}$ Noteworthy, FS3P-A/C showed the highest photothermal effect due to the presence of gold NPs with plasmon resonance tenability and high photothermal conversion efficiency. ${ }^{59,60}$

To manifest the influence of NPs concentration and NIR power density on photothermal heating effect, six kinds of NPs were tested with two different operating conditions: i) standard power density of NIR and low concentration of NPs $\left(1.5 \mathrm{~W} / \mathrm{cm}^{2}\right.$ and $\left.2.5 \mathrm{mg} / \mathrm{mL}\right)$, ii) high power density of NIR and standard concentration of NPs $\left(2.0 \mathrm{~W} / \mathrm{cm}^{2}\right.$ and $\left.5 \mathrm{mg} / \mathrm{mL}\right)$. Then, standard power density and concentration were considered as the values of $1.5 \mathrm{~W} / \mathrm{cm}^{2}$ and $5 \mathrm{mg} / \mathrm{mL}$, respectively. In the case of the standard power density of NIR $\left(1.5 \mathrm{~W} / \mathrm{cm}^{2}\right)$ and low concentration of NPs $(2.5 \mathrm{mg} / \mathrm{mL})$ shown in Supplementary Figure S3A, most NPs exhibited the lower photothermal efficiency in comparison to the standard case shown in Figure 3A. However, both FS3P-A/C and S3P-A/C NPs still exhibited a distinct photothermal effect due to the presence of plasmonic gold NPs, ie, the solution temperatures of both NPs increased to $56.1^{\circ} \mathrm{C}$ and $51.3^{\circ} \mathrm{C}$, respectively, after 10 minutes irradiation of NIR light. In the case of the high power density of NIR $\left(2.0 \mathrm{~W} / \mathrm{cm}^{2}\right)$ and the standard concentration of NPs $(5 \mathrm{mg} / \mathrm{mL})$ shown in Figure S3B, all the NPs exhibited the stronger photothermal effects in comparison to the standard case shown in Figure $3 \mathrm{~A}$, ie, all the solution temperatures increased over $50^{\circ} \mathrm{C}$ except for the MSN solution. As expected, $\mathrm{Fe}_{3} \mathrm{O}_{4}$ NPs induced the increase of solution temperature up to 63.4 ${ }^{\circ} \mathrm{C}$. Notably, FS3-based NPs with both gold and $\mathrm{Fe}_{3} \mathrm{O}_{4}$ (ie, FS3P-A) exhibited the highest solution temperature of $83.3^{\circ} \mathrm{C}$ after NIR irradiation $\left(2.0 \mathrm{~W} / \mathrm{cm}^{2}\right)$.

\section{$\mathrm{pH}$-Controlled Release Effect}

The release profiles of cisplatin from SP/C, FS3P-G/C, and FS3P-A/C were measured in PBS at $\mathrm{pH} 5.5$ and $\mathrm{pH}$ 7.4, respectively. As seen from Figure 3B, the released fraction of cisplatin from $\mathrm{SP} / \mathrm{C}$ was slightly higher at $\mathrm{pH} 7.4$ than at $\mathrm{pH} 5.5$, but the difference was not distinguishable. At 5 hours, $\sim 21.2 \%$ of cisplatin released from the SP/C. At 25 hours, the released cisplatin fraction increased to $\sim 51 \%$ and asymptotically approached $\sim 73 \%$ at 90 hours. On the other hand, FS3P-G/C exhibited a much higher release fraction at $\mathrm{pH} 5.5$ than that at $\mathrm{pH} 7.4$, whereas FS3P-A/ $\mathrm{C}$ did not show a clear difference in the release fractions between $\mathrm{pH} 7.4$ and $\mathrm{pH} 5.5$.

For the in-vitro release test of FS3P-A/C at 5 hours, the release fraction was $11.6 \%$ at $\mathrm{pH} 7.4$, but the release fraction slightly increased to $13.5 \%$ at $\mathrm{pH} 5.5$. The small disparity of release fraction between $\mathrm{pH} 5.5$ and $\mathrm{pH} 7.4$ was maintained up to 50 hours. Then, the release fraction (at $\mathrm{pH} 5.5$ ) approached the saturation value of $34.0 \%$ at 80 hours, whereas the release fraction (at $\mathrm{pH}$ 7.4) more quickly reached an asymptotic value of $26.6 \%$ at 60 hours. For the in-vitro release test of FS3P-G/C at 10 hours, the release fraction increased to $24.0 \%$ at $\mathrm{pH} 5.5$ when compared with the release fraction of $14.2 \%$ at $\mathrm{pH}$ 7.4. The divergence in the release fraction increased with release times. At 30 hours, the release fraction was 30.3\% at $\mathrm{pH} 5.5$ and $24.4 \%$ at $\mathrm{pH} 7.4$, and finally reached a saturation value of $39 \%(\mathrm{pH} 5.5)$ and $28.1 \%$ (at $\mathrm{pH} 7.4$ ) after 80 hours.

Regarding the physicochemical structure of FS3P-G/C, amino groups in PDA tend to be deprotonated at neutral $\mathrm{pH}$ 7.4, but protonated at acidic $\mathrm{pH}$ 5.5. Thus, the electrostatic (or hydrogen-bonding) interactions between functional groups of PDA and APTMS-FITC complex would be weakened (or broken) under acidic $\mathrm{pH}$ condition, consequently leading to a faster release of cisplatin at $\mathrm{pH} 5.5$ than at $\mathrm{pH} 7.4$ (Figure 3D). ${ }^{22,61}$ In addition, acidic $\mathrm{pH}$ condition could induce more weakened interaction between GO nanosheets and PDA layer, resulting in more release of cisplatin at $\mathrm{pH}$ 5.5. Thus, the release behavior of FS3-drug system with PDA/GO double layers was strongly dependent on the $\mathrm{pH}$ of surrounding solution. ${ }^{62}$

Figure S4A showed the release profiles of FS3P/C and FS3P-A/C in PBS at $\mathrm{pH} 7.4$ and $\mathrm{pH} 5.5$, respectively. In 
general, the release rate of $\mathrm{FS} 3 \mathrm{P} / \mathrm{C}$ was faster than that of FS3P-A/C, and the release fraction at $\mathrm{pH} 5.5$ was higher at $\mathrm{pH}$ 7.4. At $\mathrm{pH} 7.4$, only $12.9 \%$ of cisplatin released from FS3P-A/C at 10 hours, but the release fraction of cisplatin from $\mathrm{FS} 3 \mathrm{P} / \mathrm{C}$ was $17.2 \%$. At 30 hours, the release fraction reached $21.6 \%(\mathrm{FS} 3 \mathrm{P}-\mathrm{A} / \mathrm{C})$ and $24.2 \%(\mathrm{FS} 3 \mathrm{P} / \mathrm{C})$, respectively, followed by a gradual increase to an asymptotic value of $26.8 \%$ (with $\mathrm{Au} \mathrm{NPs}$ ) and $30.7 \%$ (without $\mathrm{Au}$ NPs) at 70 hours. At pH 5.5, however, the release fractions were $15.2 \%$ (FS3P-A/C) and $21.2 \%(\mathrm{FS} 3 \mathrm{P} / \mathrm{C})$ at 10 hours. The release fractions further increased to $23.5 \%$ (with gold) and $28.3 \%$ (without gold) at 30 hours, finally approaching an asymptotic value of $32.8 \%$ (with gold) and $37.4 \%$ (without gold) at 70 hours.

In the case of FS3P-A/C, gold NPs were deposited on the outer surface of PDA layer. Thus, gold NPs played as a blocking layer which partially hindered the release of cisplatin from the FS3-drug system. As a result, the release rate of FS3P-A/C was lower than that of $\mathrm{FS} 3 \mathrm{P} / \mathrm{C}$ at both $\mathrm{pH} 7.4$ and $\mathrm{pH} 5.5$.

\section{NIR Irradiation Controlled Release Effect}

In vitro release tests were carried out with or without irradiation of NIR light, as shown in Figure 3C. The release fractions of cisplatin from FS3P-G/C and FS3P$\mathrm{A} / \mathrm{C}$ were significantly increased by periodic irradiation of NIR light $\left(808 \mathrm{~nm}, 1.5 \mathrm{~W} / \mathrm{cm}^{2}\right)$ for 10 minutes at 10,20 , and 30 hours, respectively. The dotted lines shown in Figure $3 \mathrm{C}$ indicate the temperature variation of the solution by periodic NIR irradiation for 10 minutes.

In the case of FS3P-A/C at $\mathrm{pH} 5.5$, the released cisplatin fraction slowly increased to $15.1 \%$ for 10 hours. At the first NIR irradiation at 10 hours, the cisplatin release fraction rapidly increased to $45.9 \%$ by three-fold. When a NIR laser system turned off, the solution temperature decreased to $31.2^{\circ} \mathrm{C}$ within 3 hours. After the first NIR irradiation, the release fraction of cisplatin slowly increased to $51.5 \%$ for 20 hours, but the release fraction was much higher than that of normal case without NIR irradiation (19.7\%). At the second NIR irradiation at 20 hours, the release fraction again jumped to $69.0 \%$ within 10 minutes. Afterwards, NIR-induced release fraction gradually increased from $71.5 \%$ to $75.5 \%$ by the third NIR irradiation for 10 minutes. The release fraction of cisplatin gradually approached to an asymptotic value of $77.8 \%$ at 50 hours. On the other hand, the released cisplatin fraction without NIR irradiation slowly reached to $15.2 \%$ at 10 hours, $23.5 \%$ at 30 hours, and finally reached an asymptotical value of $34.0 \%$ at 80 hours.

Under the irradiation of NIR light at $\mathrm{pH} 5.5$, GOcoated FS3 (FS3P-G/C) exhibited a slower release rate than that of gold-coated FS3 (FS3P-A/C). The disparity of release rate increased with periodic numbers of NIR irradiation. At the first irradiation of NIR: $40.6 \%$ (GO) $<45.9 \%$ (Au NPs); at the second irradiation of NIR: $54.4 \%$ (GO) $<69.0 \%$ (Gold); at the third irradiation of NIR: $61.2 \%$ (GO) $<75.5 \%$ (Au NPs). The release fraction of cisplatin from FS3P-A/C at $\mathrm{pH} 5.5$ without NIR irradiation was less than $\sim 30 \%$ at 80 hours of release times.

In summary, GO-wrapped FS3 (FS3P-G/C) exhibited high sensitivity of release rate at acidic $\mathrm{pH} 5.5$ (Figure 3D1). On the other hand, Au NPs-coated FS3 (FS3P-A/C) exhibited more stable and sustained release at both $\mathrm{pH} 5.5$ and $\mathrm{pH}$ 7.4, but exhibited extremely sensitive release behavior under NIR irradiation, as shown in Table 1.

Table I Summary of Drug Release Data for Each Type of Particles Under Different Conditions of Time vs pH and NIR Irradiation

\begin{tabular}{|c|c|c|c|c|c|c|c|}
\hline \multirow[t]{2}{*}{$\begin{array}{l}\text { Kind of } \\
\text { Nanoparticle }\end{array}$} & \multirow[t]{2}{*}{ Compositions } & \multicolumn{3}{|c|}{ pH Effect } & \multicolumn{3}{|c|}{$\begin{array}{l}\text { NIR Irradiation Effect } \\
(\mathrm{pH} 5.5)\end{array}$} \\
\hline & & pH & $\begin{array}{l}\text { Release } \\
\text { Efficiency } \\
\text { (\%) }\end{array}$ & $\begin{array}{l}\text { Release } \\
\text { Saturation } \\
\text { Time (hours) }\end{array}$ & $\begin{array}{l}3 \text { Times } \\
\text { of NIR } \\
\text { (on/off) }\end{array}$ & $\begin{array}{l}\text { Release } \\
\text { Efficiency } \\
(\%)\end{array}$ & $\begin{array}{l}\text { Release } \\
\text { Saturation } \\
\text { Time (hours) }\end{array}$ \\
\hline SP/C & Silica NPs, Polydopamine, Cisplatin & $\begin{array}{l}\mathrm{pH} 5.5 \\
\mathrm{pH} 7.4\end{array}$ & $\begin{array}{l}73.62 \pm 0.96 \\
71.30 \pm 1.34\end{array}$ & $\begin{array}{l}80 \\
80\end{array}$ & $\begin{array}{l}- \\
-\end{array}$ & $\begin{array}{l}- \\
-\end{array}$ & - \\
\hline FS3P-G/C & $\begin{array}{l}\text { Fe3O4, Silica NPs, APTMS-FITC, } \\
\text { Polydopamine, Graphene oxide, } \\
\text { Cisplatin }\end{array}$ & $\begin{array}{l}\mathrm{pH} 5.5 \\
\mathrm{pH} 7.4\end{array}$ & $\begin{array}{l}39.23 \pm 0.43 \\
27.85 \pm 0.43\end{array}$ & $\begin{array}{l}80 \\
60\end{array}$ & $\begin{array}{l}\text { off } \\
\text { on }\end{array}$ & $\begin{array}{l}39.23 \pm 0.43 \\
64.07 \pm 0.75\end{array}$ & $\begin{array}{l}80 \\
30\end{array}$ \\
\hline FS3P-A/C & $\begin{array}{l}\mathrm{Fe}_{3} \mathrm{O}_{4} \text {, Silica NPs, APTMS-FITC, } \\
\text { Polydopamine, Au NPs, Cisplatin }\end{array}$ & $\begin{array}{l}\mathrm{pH} 5.5 \\
\mathrm{pH} 7.4\end{array}$ & $\begin{array}{l}34.02 \pm 1.66 \\
26.66 \pm 0.91\end{array}$ & $\begin{array}{l}80 \\
60\end{array}$ & $\begin{array}{l}\text { off } \\
\text { on }\end{array}$ & $\begin{array}{l}34.02 \pm 1.66 \\
77.46 \pm 0.76\end{array}$ & $\begin{array}{l}80 \\
30\end{array}$ \\
\hline
\end{tabular}


Thus, core-shell FS3-drug systems (eg, FS3P-G/C and FS3P-A/C) can be potentially applied for targeted tumor therapy as chemo-photothermal agents with highly sensitive stimuli (pH and NIR)-responsiveness (Figure 3D-2).

\section{Kinetic Model Applications to Cisplatin Release}

The release kinetics was analyzed by an empirical Hill equation: $\frac{Q_{t}}{Q_{\infty}}=\frac{Q_{\text {max }} t^{\prime}}{Q_{1 / 2}+t^{\prime}}$

where $\mathrm{Q}_{\max }$ is the maximum amount of drug release, $\mathrm{Q}_{1 / 2}$ is the time required for $50 \%$ drug release, and $\gamma$ is a sigmoidicity factor. The Hill equation can suitably describe release profiles with sigmoid behavior. ${ }^{63}$

The cisplatin release profiles can also be fitted by a power-law equation, based on the Korsmeyer-Peppas (K-P) model, which is usually applied to predict the diffusion mechanism in anomalous drug release kinetics: $Q_{t} Q_{\infty}=k_{R} t^{n}$

where $\mathrm{Q}_{t} / \mathrm{Q}_{\infty}$ is the normalized fraction of the drug release, $k_{R}$ is the relaxation rate constant, and $n$ is the release exponent. In the K-P model, the value of $n$ characterizes the release mechanism. In the case of a spherical matrix, $\mathrm{n}=0.43$ for Fickian diffusion, and $0.43<\mathrm{n}<0.85$ for non-Fickian transport. ${ }^{22}$

As shown in Supplementary Figure S4B, the cisplatin release from $\mathrm{SP} / \mathrm{C}$ follows sigmoid behavior fitted by Hill Equation (1), in which a sigmoidicity factor was 2.1 (Supplementary Table S2). At the first stage of release fraction, it shows a slow release behavior below 5\% of cisplatin release fraction. This slow stage is usually caused by mechanical lag processing including disaggregation of mesoporous NPs and/or disintegration of PDA coating. After then, SP/C without APTMS-FITC conjugates showed a rapid release of cisplatin, kind of a burst effect, up to a saturation value later, whereas $\mathrm{FS} 3 \mathrm{P} / \mathrm{C}$ showed a retarded release and finally reached saturation after a longperiod of time (around 7 days). Thus, the release kinetics of FS3P/C were analyzed by the K-P model with a release exponent of $n=0.64$ (Table S2).

In the beginning, it may start off at a rapid rate and slow down (burst effect), start off immediately, or it may take time to build up (time lag).

According to Supplementary Figure S4B, the cisplatin release kinetics of FS3P-G/C and FS3P-A/C were fitted by the K-P model (2), in which a release fraction less than $60 \%$ was used. The fitted release exponents of FS3P-G/C and FS3P-A/C were $\mathrm{n}=0.62$ and $\mathrm{n}=0.71$, respectively, that were higher than 0.43 , indicating that the release kinetics shows non-Fickian diffusion behavior. In summary, the release kinetics of FS3-based NPs can be controlled by APTMS-FITC internal conjugates with PDA layer, and further retarded by the additional diffusion barriers of external GO and/or Au NPs layer.

\section{Fluorescent Images, In vitro Anticancer Efficacy, and Protein Corona Analysis} Cellular Uptake and Intracellular Distribution

Cellular uptake of SP/C, FS3P-G/C, FS3P-A/C, and FS3PG-E/C was incubated with HeLa cells for 4 hours, and confocal fluorescence images (CLSM) were taken. All treated groups' emitted green fluorescence in HeLa cells, indicating the direct cellular uptake of FS3-based nanocarriers, as shown in Figure 4, presenting good effectiveness of the NPs. Green (FITC) fluorescence either from NPs in the cell cytoplasm and blue fluorescence from DAPI in the cell nuclei were simultaneously observed. The merged image of blue and green fluorescences revealed that the majority of the NPs including SP/C (Figure 4A), FS3P-G/C (Figure 4B), FS3P$\mathrm{A} / \mathrm{C}$ (Figure 4C), and FS3P-G-E/C (Figure 4D) were significantly accumulated in HeLa cells, whereas no fluorescence was observed in HEK293 cells treatment with SP/C (Supplementary Figure S5A), FS3P-G/C (Supplementary Figure S5B), FS3P-A/C (Supplementary Figure S5C), and FS3P-G-E/C (Supplementary Figure S5D) under the same conditions. Remarkably, when compared to that of ab-unconjugated counterpart (Figure 4B), the internalization of EGFconjugated FS3P-G/C (Figure 4D) was more retained in the treated cells, indicative of the effectiveness of ab on cancer cell targeting and treatment.

The cellular uptake of SP/C, FS3P-G/C, FS3P-A/C, and FS3P-G-E/C NP was also confirmed by flow cytometry analysis. The fluorescence intensity of single cell emission detected by flow cytometry that would be a good indication of the amount of NPs internalized by each cell. As shown in Figure 4 (right panel), the peak of the fluorescence intensity was dramatically increased between 4 hours and 24 hours incubation with the NPs, suggesting the promoted NP internalization by HeLa cells. Using flow cytometry and confocal microscopy, the results totally reveal that fluorescently labeled FITC NPs were significantly internalized in cancer cells, indicating the impressive efficiency of drug delivery.

Furthermore, to confirm the targeted delivery of NPs into the cells, as-prepared samples (such as SP/C, FS3P-G/ C, FS3P-A/C, and FS3P-G-E/C were analyzed by TEM. According to the TEM images of cells treated with NPs, 


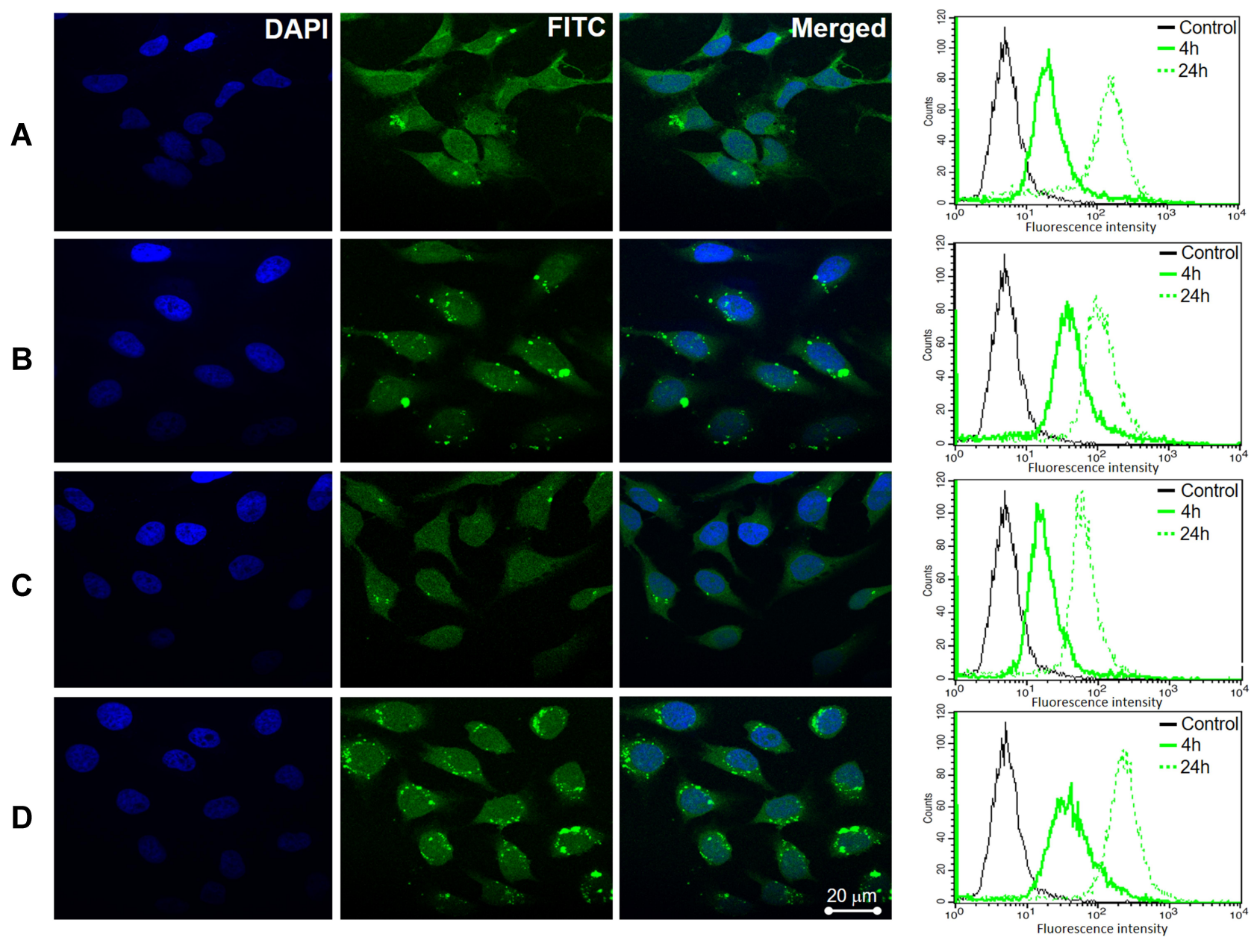

Figure 4 Confocal microscopy imaging and flow cytometry analysis of HeLa cells after incubation with as-prepared samples: (A) SP/C, (B) FS3P-G/C, (C) FS3P-A/C, and (D) FS3P-G-E/C.

all three NPs were localized mainly in the cytoplasmic matrix covering the nucleus (orange arrows), while the same behavior was not observed in the control cells (Figure 5), indicating that three NPs were well trapped in cancerous cells but not inside the nucleus. The increased cellular uptake was usually accorded with surface properties of NPs. Compared to untreated cells (Figure 5A), some small aggregates were observed in the cells incubated with SP/C (Figure 5B), while a few large aggregates were localized nearby the nucleus of the cells incubated with GO-coated FS3 (Figure 5C), FS3P-A/C (Figure 5D), and EGFR ab-conjugated FS3 (Figure 5E). Correlating these TEM images with confocal images and flow cytometry analysis (Figure 4), the intracellular distribution of NPs seemed to be locally disrupted and discontinuous because of large aggregates of NPs that were capable of crossing cellular membranes. Supplementary Figure S6 supports these observations by providing detailed data of
TEM images of the cells treated with the SP/C (Supplementary Figure S6A), FS3P-G/C (Supplementary Figure S6B), and FS3P-G-E/C (Supplementary Figure S6C).

\section{In vitro Anticancer Efficacy of the Various NPs}

To evaluate the anticancer effects of those NPs, the CellTiter-Glo® Luminescent reagent was used to measure adenosine triphosphate (ATP) as an indication of cell viability ${ }^{47}$ of HeLa, SH-SY5Y, and kidney HEK293 cell lines after the treatment. As seen from Figure 6A, MSN and MAF did not affect the cell viability irrespective of the different surface modifications. Furthermore, these nanocarriers at high dosage of $10 \mu \mathrm{g} / \mathrm{mL}$ did not affect the cell viability, ie, HeLa, SH-SY5Y, and HEK293 were still viable up to more than $85 \%$. This suggested that FS3based nanocarriers revealed low cytotoxicity toward both cancerous cells and normal cells. The viability test showed that FS3 was a safe nanocarrier, hardly causing any 

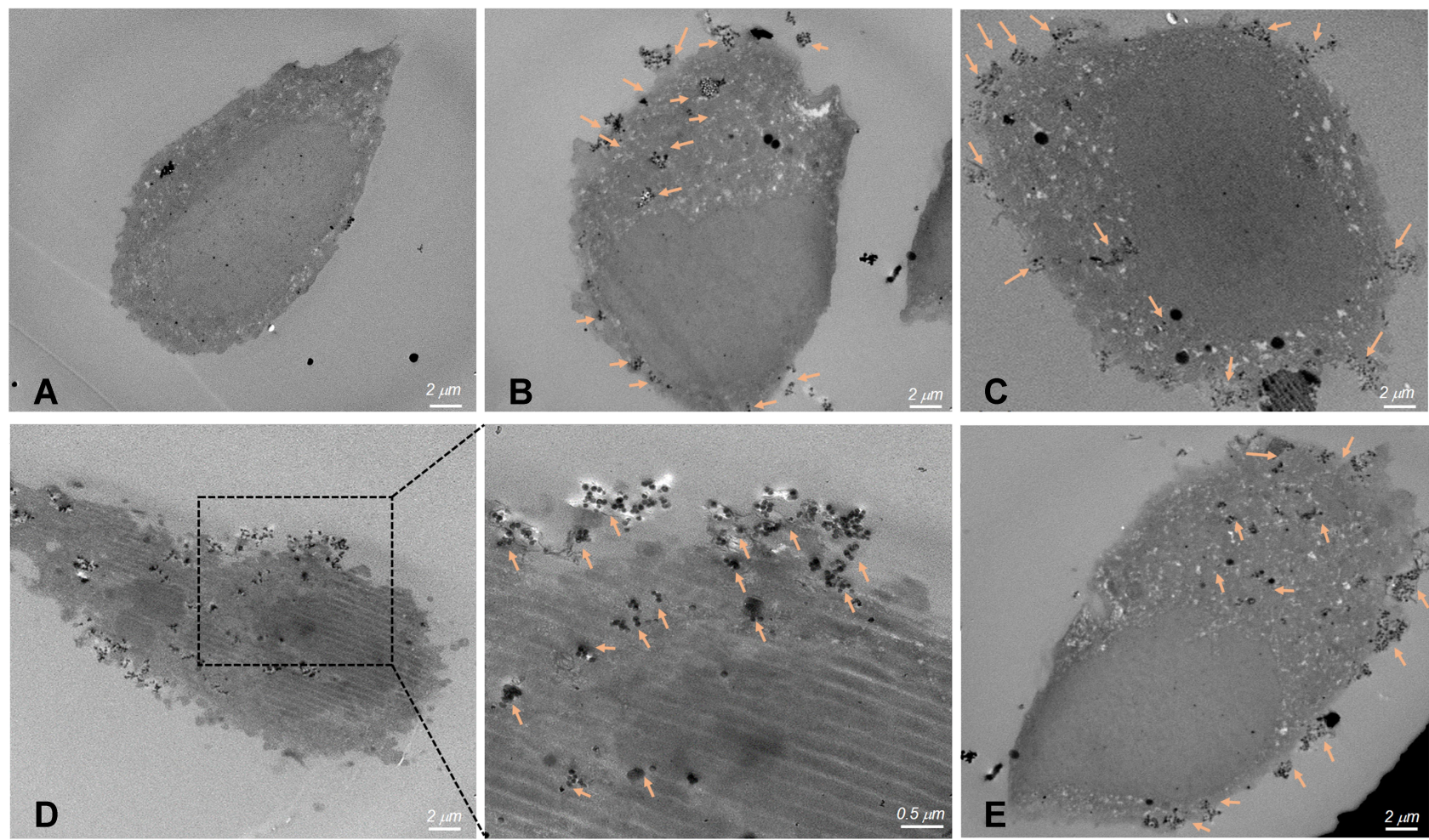

Figure 5 Thin-section TEM images of cell incubated with magnetic mesoporous silica nanoparticles. (A) Control cells without nanoparticles, (B) SP/C, (C) FS3P-G/C, (D) FS3P-A/C, and (E) FS3P-G-E/C. Arrows denote metal oxide particles or particulate matter.

cytotoxicity on its own. SP/C, FS3P-G/C, and FS3P-G-E/ $\mathrm{C}$ displayed the discrepant anti-proliferation efficiency mediated by the drug release from the FS3 samples, demonstrating substantially enhanced cytotoxicity to both cancer cells, HeLa and SH-SY5Y, in a concentrationdependent manner. When the concentrations of $\mathrm{SP} / \mathrm{C}$, FS3P-G/C, and FS3P-G-E/C increased from 2.5 to 10 $\mu \mathrm{g} / \mathrm{mL}$, the viability of both HeLa and SH-SY5Y cancer cell lines decreased sharply from $\sim 65 \%$ to $\sim 10 \%$, from $\sim 60 \%$ to $\sim 8 \%$, and from $\sim 40 \%$ to less than $7 \%$, respectively. The surface groups of the SP/C samples induced cytotoxicity against both HeLa and SH-SY5Y cancer cell lines through the final intracellular delivery and biological function of the material, suggesting its potential clinical utility as an anticancer agent. Besides, GO can induce the generation of reactive oxygen species (ROS) in cells and the exposure of cancer cells to GO can lead to cancer cell killing by enhancing the cytotoxicity effect exerted through the induction of DNA damage. ${ }^{64}$

In addition, in the case of FS3P-A/C, the HeLa and SH-SY5Y cells were still viable up to more than $65 \%$ at concentration ranges from 0.625 to $5 \mu \mathrm{g} / \mathrm{mL}$, and over $50 \%$ cells died at the highest concentration of $10 \mu \mathrm{g} / \mathrm{mL}$. When compared to FS3P-G/C, gold- deposited FS3 showed a lower inhibition effect on the proliferation of HeLa and SH-SY5Y cancer cells at $5 \mu \mathrm{g} / \mathrm{mL}$, probably due to the strong aggregation behavior of gold NPs.

Gold NPs were promising candidates for a number of consumer and food products due to their inertness at low doses. In general, the cytotoxicity of gold NPs depended on physicochemical properties such as particle size and surface chemistry. Many toxicity studies demonstrated that gold NPs were mostly inert after acute exposures (shortterm treatment), as long as the NPs were above $4-5 \mathrm{~nm}$ in diameter. ${ }^{65-67}$ This acute toxicity could be ascribed to the use of very high concentrations and different cell type sensitivities. ${ }^{67-70}$ On the other hand, high-doses of FS3P$\mathrm{A} / \mathrm{C}$ may be more effective in cell death as an acute burst of exposure. On this basis, the concentrations of FS3P-A/C $(10 \mu \mathrm{M})$, at which both cancers revealed $22 \%$ viability, were selected for further treatment-induced therapy. More importantly, the lower concentrations of FS3P-A/C (5 $\mu \mathrm{g} /$ $\mathrm{mL}$ ) killed the vast majority of cells under $808 \mathrm{~nm}$ NIR laser irradiation at $1.5 \mathrm{~W} / \mathrm{cm}^{2}$ for 5 minutes (Figure 6B, third upper panel). This figure was dramatically increased after irradiation for more than 10 minutes compared to the corresponding control experimental samples without laser 
A HeLa cells
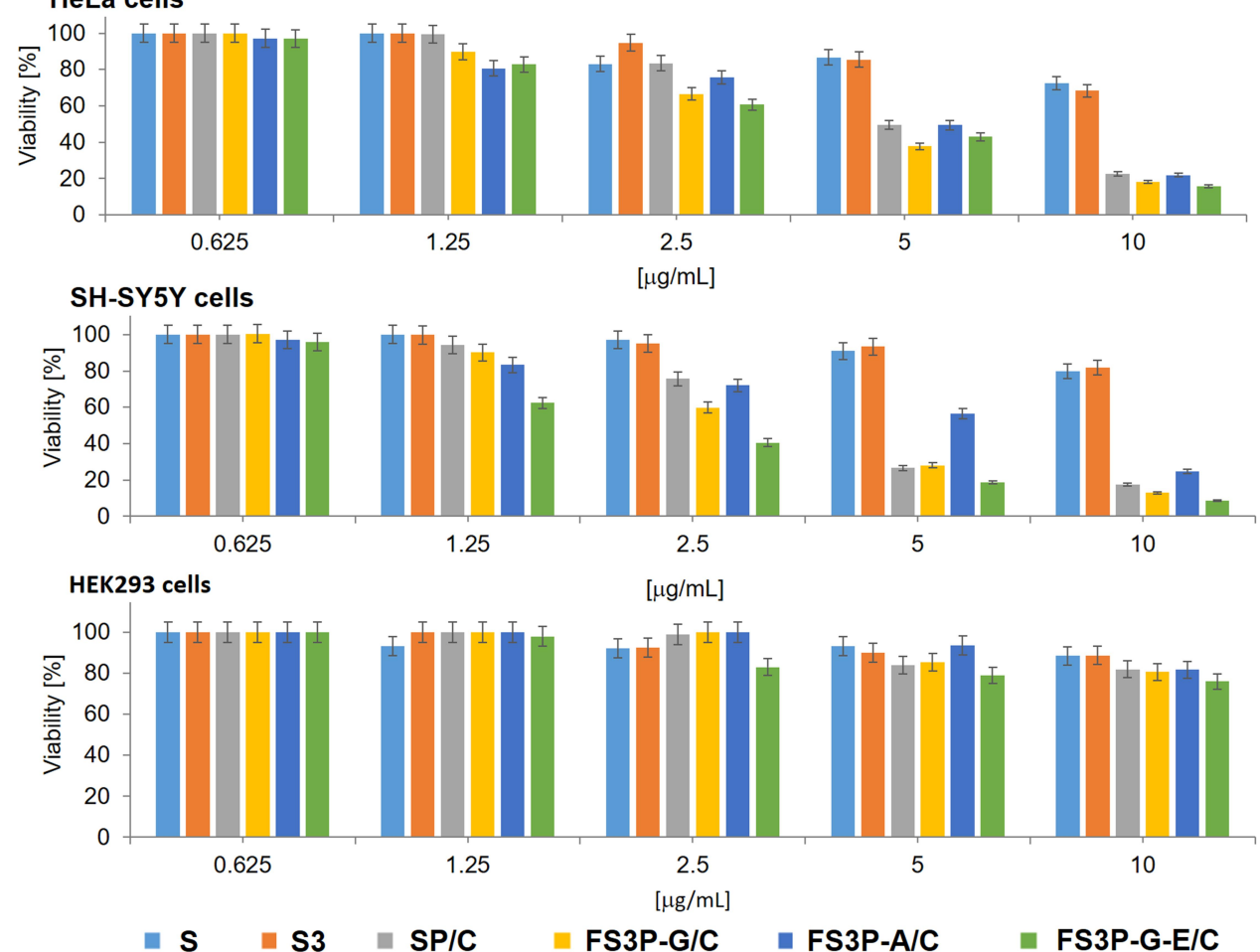

B
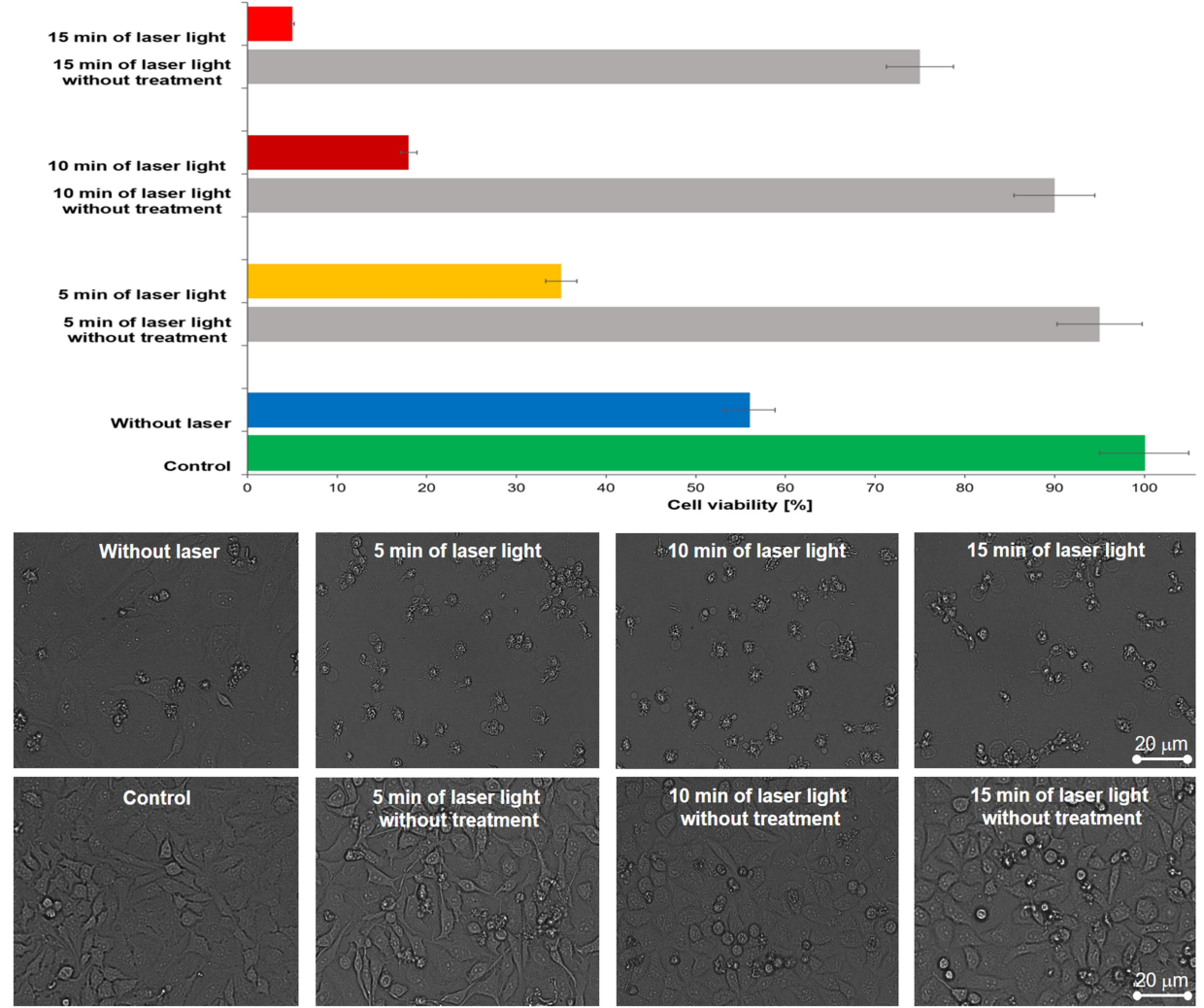

Figure 6 (A) Cytotoxicity against HeLa, SH-SY5Y, and HEK293 cells lines induced by different nanoparticles S, S3, SP/C, FS3P-G/C, FS3P-A/C, and FS3P-G-E/C at their concentrations ranging from 0.625 to $10 \mu \mathrm{g} / \mathrm{mL}$. (B) Cell viability of HeLa cells (the up panel) and their morphological observation (the down panel) incubated with or without FS3P-A/C (concentration $5 \mu \mathrm{g} / \mathrm{mL}$ ) with or without $808 \mathrm{~nm}$ NIR laser irradiation at $1.5 \mathrm{~W} / \mathrm{cm}^{2}$ for 5,10 , and 15 minutes. 
irradiation, suggesting its photothermal ablation may be effective in the cancer cells. The cell morphology was further observed by light microscope. In the control group, there was no noticeable change with the exception of 15 minutes in the NIR-irradiated group (Figure 6B, lower panel) was observed. While approximately 55\% dead cells were observed after treatment of $5 \mu \mathrm{g} / \mathrm{mL}$ of FS3P-A/C without $808 \mathrm{~nm}$ NIR laser irradiation, this figure was rapidly increased to over $70 \%$ under NIR laser irradiation at $1.5 \mathrm{~W} / \mathrm{cm}^{2}$ for 5,10 , or 15 minutes (Figure 6B in the upper panel), indicating the strong effect of photothermal ablation on cancer cell cytotoxicity. Taken together, these results strongly suggest that the phototoxicity was mainly due to irradiation of extracellular FS3P-A/ $\mathrm{C}$ that damaged cell membranes, indicating that the cytotoxic death effect on cancer cells was clearly promoted by photothermal ablation by FS3P-A/C under NIR irradiation. On the other hand, the potential ability of FS3P-G/C for laser-induced heating was also tested through the same model. As shown in Supplementary Figure S7, cell viability was gradually decreased (approximately 50\%) when the irradiation time was increased up to 15 minutes only. However, the cell viability was also decreased by NIR light exposure followed by 15 minutes irradiation without treatments (Figure 6B and Supplementary Figure S7). Conclusively, with the excellent laser-induced heating properties, FS3P-A/C could be a novel promising agent for photothermal therapy. ${ }^{71}$

Figure 6A also reveals the viability of HEK293 cells treated with NPs at different dosages. Interestingly, almost all cells were still alive at the whole range of NP concentrations, indicating that drug-loaded FS3 showed no obvious cytotoxicity toward normal cells. The cell viability was more than $80 \%$ even at $10 \mu \mathrm{g} / \mathrm{mL}$ of NP concentration. These results suggested that the FS3-based nanocarriers were non-toxic materials at low concentrations and slightly toxic at high concentrations $(10 \mu \mathrm{g} / \mathrm{mL}) .^{72,73}$ Thus, FS3s as a drug platform to kill cancer cells were effective at concentrations lower than $10 \mu \mathrm{g} / \mathrm{mL}$, implying their biocompatibility with normal cells and supporting new developments in the biotechnological, pharmaceutical, and biomedical industries. ${ }^{74,75}$

\section{Conclusions}

In this work, core-shell type mesoporous silica nanocarriers were developed for fluorescent imaging, stimuli-responsive drug release, magnetic separation, antibody targeting, and chemo-photothermal therapeutics. Firstly, magnetic mesoporous silica nanoparticles were prepared by coating a $\mathrm{Fe}_{3} \mathrm{O}_{4}$ core with a mesoporous silica shell, followed by grafting with fluorescent conjugates, so-called FS3. The resulting FS3 was preloaded with therapeutic cisplatin and coated with polydopamine (PDA) layer, so-called $\mathrm{FS} 3 \mathrm{P} / \mathrm{C}$. Eventually, graphene oxide-wrapped FS3P/C (FS3P-G/C) exhibited high sensitivity in the dual stimuli ( $\mathrm{pH}, \mathrm{NIR}$ )responsive controlled release behavior, ie, showing the increased release rate when the solution $\mathrm{pH}$ was changed from $\mathrm{pH} 7.4$ to $\mathrm{pH} 5.5$ and enhancement of release rate under NIR irradiation ( $\left.808 \mathrm{~nm}, 1.5 \mathrm{~W} / \mathrm{cm}^{2}\right)$ for 10 minutes. On the other hand, gold-coated FS3P/C (FS3P-A/C) exhibited more stable release behavior, irrespective of $\mathrm{pH}$ changes, and exhibited a much more enhanced release rate under the same NIR irradiation, because of its high photothermal heating effect. Notably, FS3P-A/C showed strong NIR absorption, enabling photothermal destruction of HeLa cells by its chemo-photothermal therapeutic effects under NIR irradiation $\left(808 \mathrm{~nm}, 1.5 \mathrm{~W} / \mathrm{cm}^{2}\right)$. The selective uptake of FS3-based nanocarriers was confirmed in various cancer cell lines by the images obtained from CLSM, flow cytometry, and TEM instruments. Cisplatin-free FS3-based nanocarriers revealed good cellular uptake and low cytotoxicity against cancerous HeLa and SH-SY5Y cells, but showed no obvious toxicity to normal HEK293 cells. Along with the facile synthesis of FS3-based nanocarriers, the integration of all these strategies into one single unit will be a prospective candidate for biomedical applications, especially in chemo-photothermal therapeutics, targeted delivery, and stimuli-responsive controlled drug release against multiple cancer cell types.

\section{Funding}

This study was supported financially by the Korea Institute of Energy Technology Evaluation and Planning (KETEP) and the Ministry of Trade, Industry, and Energy (MOTIE) of the Republic of Korea [grant no. 20194030202440] and the National Research Foundation of Korea (NRF2020R1A2B5B01002463).

\section{Disclosure}

The authors declare no conflicts of interest for this work.

\section{References}

1. Rodzinski A, Guduru R, Liang P, et al. Targeted and controlled anticancer drug delivery and release with magnetoelectric nanoparticles. Sci Rep. 2016;6(1):20867. doi:10.1038/srep20867

2. Mo Y, Wang H, Liu J, et al. Controlled release and targeted delivery to cancer cells of doxorubicin from polysaccharide-functionalised singlewalled carbon nanotubes. J Mater Chem B. 2015;3(9):1846-1855. doi:10.1039/C4TB02123A 
3. Zhang Q, Liu J, Yuan K, Zhang Z, Zhang X, Fang X. A multicontrolled drug delivery system based on magnetic mesoporous Fe3O4 nanopaticles and a phase change material for cancer thermochemotherapy. Nanotechnology. 2017;28(40):405101. doi:10.1088/ 1361-6528/aa883f

4. Ho CC, Ding SJ. The $\mathrm{pH}$-controlled nanoparticles size of polydopamine for anti-cancer drug delivery. J Mater Sci Mater Med. 2013;24 (10):2381-2390. doi:10.1007/s10856-013-4994-2

5. Weaver CL, LaRosa JM, Luo X, Cui XT. Electrically controlled drug delivery from graphene oxide nanocomposite films. ACS Nano. 2014;8(2):1834-1843. doi:10.1021/nn406223e

6. He D, He X, Wang K, Zou Z, Yang X, Li X. Remote-controlled drug release from graphene oxide-capped mesoporous silica to cancer cells by photoinduced pH-jump activation. Langmuir. 2014;30(24):71827189. doi: $10.1021 / 1 \mathrm{la} 501075 \mathrm{c}$

7. Li J, Mooney DJ. Designing hydrogels for controlled drug delivery. Nat Rev Mater. 2016;1(12):16071.

8. Pimenta AFR, Ascenso J, Fernandes JCS, Colaco R, Serro AP, Saramago B. Controlled drug release from hydrogels for contact lenses: drug partitioning and diffusion. Int J Pharm. 2016;515(12):467-475. doi:10.1016/j.ijpharm.2016.10.047

9. Chen FM, Liu X. Advancing biomaterials of human origin for tissue engineering. Prog Polym Sci. 2016;53:86-168. doi:10.1016/j. progpolymsci.2015.02.004

10. Han R, Yi H, Shi J, et al. pH-responsive drug release and NIRtriggered singlet oxygen generation based on a multifunctional core-shell-shell structure. Phys Chem Chem Phys. 2016;18 (36):25497-25503. doi:10.1039/C6CP05308D

11. Zeng X, Liu G, Tao W, et al. A drug-self-gated mesoporous antitumor nanoplatform based on $\mathrm{pH}$-sensitive dynamic covalent bond. $A d v$ Funct Mater. 2017;27(11):1605985. doi:10.1002/adfm.201605985

12. Baeza A, Manzano M, Colilla M, Vallet-Regí M. Recent advances in mesoporous silica nanoparticles for antitumor therapy: our contribution. Biomater Sci. 2016;4(5):803-813. doi:10.1039/C6BM00039H

13. Cheng W, Nie J, Gao N, et al. A multifunctional nanoplatform against multidrug resistant cancer: merging the best of targeted chemo/gene/ photothermal therapy. Adv Funct Mater. 2017;27(45):1704135. doi:10.1002/adfm.201704135

14. Zhou Y, Quan G, Wu Q, et al. Mesoporous silica nanoparticles for drug and gene delivery. Acta Pharm Sin B. 2018;8(2):165-177. doi:10.1016/j.apsb.2018.01.007

15. Wang $\mathrm{Y}, \mathrm{Gu} \mathrm{H}$. Core-shell-type magnetic mesoporous silica nanocomposites for bioimaging and therapeutic agent delivery. Adv Mater. 2015;27(3):576-585. doi:10.1002/adma.201401124

16. Gao Q, Xie W, Wang Y, et al. A theranostic nanocomposite system based on radial mesoporous silica hybridized with Fe3O4 nanoparticles for targeted magnetic field responsive chemotherapy of breast cancer. $R S C A d v$. 2018;8(8):4321-4328. doi:10.1039/C7RA12446E

17. Yang C, Guo W, Cui L, et al. pH-responsive magnetic core-shell nanocomposites for drug delivery. Langmuir. 2014;30(32):98199827. doi:10.1021/la501833u

18. Yu X, Zhu Y. Preparation of magnetic mesoporous silica nanoparticles as a multifunctional platform for potential drug delivery and hyperthermia. Sci Technol Adv Mater. 2016;17(1):229-238. doi:10. 1080/14686996.2016.1178055

19. Ansari L, Malaekeh-Nikouei B. Magnetic silica nanocomposites for magnetic hyperthermia applications. Int J Hyperthermia. 2017;33 (3):354-363. doi:10.1080/02656736.2016.1243736

20. Zeng X, Luo M, Liu G, et al. Polydopamine-modified black phosphorous nanocapsule with enhanced stability and photothermal performance for tumor multimodal treatments. Adv Sci. 2018;5 (10):1800510. doi:10.1002/advs.201800510

21. Jiang JH, Pi J, Jin H, Cai JY. Functional graphene oxide as cancertargeted drug delivery system to selectively induce oesophageal cancer cell apoptosis. Artif Cells Nanomed Biotechnol. 2018;46(sup3): S297-s307. doi:10.1080/21691401.2018.1492418
22. Tran AV, Shim K, Vo Thi TT, Kook JK, An SSA, Lee SW. Targeted and controlled drug delivery by multifunctional mesoporous silica nanoparticles with internal fluorescent conjugates and external polydopamine and graphene oxide layers. Acta Biomater. 2018;74:397413. doi:10.1016/j.actbio.2018.05.022

23. Wang Z, Duan Y, Duan Y. Application of polydopamine in tumor targeted drug delivery system and its drug release behavior. $J$ Control Release. 2018;290:56-74. doi:10.1016/j.jconrel.2018.10.009

24. Hogan NJ, Urban AS, Ayala-Orozco C, Pimpinelli A, Nordlander P, Halas NJ. Nanoparticles heat through light localization. Nano Lett. 2014;14(8):4640-4645. doi:10.1021/nl5016975

25. Karampelas IH, Liu K, Alali F, Furlani EP. Plasmonic nanoframes for photothermal energy conversion. J Phys Chem C. 2016;120 (13):7256-7264. doi:10.1021/acs.jpcc.5b12743

26. GhavamiNejad A, SamariKhalaj M, Aguilar LE, Park CH, Kim CS. $\mathrm{pH} / \mathrm{NIR}$ light-controlled multidrug release via a mussel-inspired nanocomposite hydrogel for chemo-photothermal cancer therapy. Sci Rep. 2016;6:33594. doi:10.1038/srep33594

27. Jiang W, Mo F, Jin X, et al. Tumor-targeting photothermal heatingresponsive nanoplatform based on reduced graphene oxide/mesoporous silica/hyaluronic acid nanocomposite for enhanced photodynamic therapy. Adv Mater Interfaces. 2017;4(20):1700425. doi:10.1002/ admi.201700425

28. Tao W, Zhu X, Yu X, et al. Black phosphorus nanosheets as a robust delivery platform for cancer theranostics. Adv Mater. 2017;29 (1):1603276. doi:10.1002/adma.201603276

29. Ma Y, Liang X, Tong S, Bao G, Ren Q, Dai Z. Gold nanoshell nanomicelles for potential magnetic resonance imaging, light-triggered drug release, and photothermal therapy. Adv Funct Mater. 2013;23(7):815-822. doi:10.1002/adfm.201201663

30. Liu H, Chen D, Li L, et al. Multifunctional gold nanoshells on silica nanorattles: a platform for the combination of photothermal therapy and chemotherapy with low systemic toxicity. Angewandte Chemie. 2011;50(4):891-895. doi:10.1002/anie.201002820

31. Jiang W, Mo F, Lin Y, Wang X, Xu L, Fu F. Tumor targeting dual stimuli responsive controllable release nanoplatform based on DNAconjugated reduced graphene oxide for chemo-photothermal synergetic cancer therapy. J Mater Chem B. 2018;6(26):4360-4367. doi:10.1039/C8TB00670A

32. NDong C, Tate JA, Kett WC, et al. Tumor cell targeting by iron oxide nanoparticles is dominated by different factors in vitro versus in vivo. PLoS One. 2015;10(2):e0115636. doi:10.1371/journal.pone.0115636

33. Rosen JE, Chan L, Shieh DB, Gu FX. Iron oxide nanoparticles for targeted cancer imaging and diagnostics. Nanomedicine:NBM. 2012;8(3):275-290. doi:10.1016/j.nano.2011.08.017

34. Wu M, Huang S. Magnetic nanoparticles in cancer diagnosis, drug delivery and treatment. Mol Clin Oncol. 2017;7(5):738-746.

35. Blanco E, Kessinger CW, Sumer BD, Gao J. Multifunctional micellar nanomedicine for cancer therapy. Exp Biol Med. 2009;234(2):123131. doi:10.3181/0808-MR-250

36. Alibakhshi A, Abarghooi Kahaki F, Ahangarzadeh S, et al. Targeted cancer therapy through antibody fragments-decorated nanomedicines. J Control Release. 2017;268:323-334. doi:10.10 16/j.jconrel.2017.10.036

37. Xiong J, Sun Q, Chen J, Li Z, Dou S. Ambient controlled synthesis of advanced core-shell plasmonic Ag@ZnO photocatalysts. CrystEngComm. 2016;18(10):1713-1722. doi:10.1039/C6CE00013D

38. Petros RA, DeSimone JM. Strategies in the design of nanoparticles for therapeutic applications. Nat Rev Drug Discov. 2010;9(8):615627. doi: $10.1038 / \mathrm{nrd} 2591$

39. Rejeeth C, Vivek R, Kannan S. A novel magnetic drug delivery nanocomplex with a cisplatin-conjugated Fe3O4 core and a PEGfunctionalized mesoporous silica shell for enhancing cancer drug delivery efficiency. $R S C A d v$. 2015;5(115):94534-94538. doi:10.10 39/C5RA19274A 
40. Kim J, Kim HS, Lee N, et al. Multifunctional uniform nanoparticles composed of a magnetite nanocrystal core and a mesoporous silica shell for magnetic resonance and fluorescence imaging and for drug delivery. Angewandte Chemie. 2008;47(44):8438-8441. doi:10.1002/ anie.200802469

41. Tran VA, Lee SW. A prominent anchoring effect on the kinetic control of drug release from mesoporous silica nanoparticles (MSNs). J Colloid Interface Sci. 2018;510:345-356. doi:10.1016/j. jcis.2017.09.072

42. Lodha A, Lodha M, Patel A, et al. Synthesis of mesoporous silica nanoparticles and drug loading of poorly water soluble drug cyclosporin A. J Pharm Bioallied Sci. 2012;4(Suppl 1):S92-S94. doi:10.4103/0975-7406.94153

43. Andersson A, Hedenmalm H, Elfsson B, Ehrsson H. Determination of the acid dissociation constant for Cis-Diammineaquachloroplatinum (I I) ion. A hydrolysis product of cisplatin. J Pharm Sci. 1994;83 (6):859-862. doi:10.1002/jps.2600830620

44. Vivero-Escoto JL, Elnagheeb M. Mesoporous silica nanoparticles loaded with cisplatin and phthalocyanine for combination chemotherapy and photodynamic therapy in vitro. Nanomaterials. 2015;5 (4):2302-2316. doi:10.3390/nano5042302

45. Sreejith S, Ma X, Zhao Y. Graphene oxide wrapping on squaraineloaded mesoporous silica nanoparticles for bioimaging. J Am Chem Soc. 2012;134(42):17346-17349. doi:10.1021/ja305352d

46. Raj V, Prabha G. Synthesis, characterization and in vitro drug release of cisplatin loaded Cassava starch acetate-PEG/gelatin nanocomposites. J Assoc Arab Univ Basic Appl Sci. 2016;21:10-16. doi:10.1016/ j.jaubas.2015.08.001

47. Nguyen NH, Nguyen TT, Ma PC, Ta QTH, Duong TH, Vo VG. Potential antimicrobial and anticancer activities of an ethanol extract from bouea macrophylla. Molecules. 2020;25(8):1996. doi:10.3390/ molecules25081996

48. Kohri M, Nannichi Y, Kohma H, et al. Size control of polydopamine nodules formed on polystyrene particles during dopamine polymerization with carboxylic acid-containing compounds for the fabrication of raspberry-like particles. Colloids Surf a Physicochem Eng Asp. 2014;449:114-120. doi:10.1016/j.colsurfa.2014.02.049

49. Lee Y, Park TG. Facile fabrication of branched gold nanoparticles by reductive hydroxyphenol derivatives. Langmuir. 2011;27(6):29652971. doi:10.1021/la1044078

50. Zhang M, Zheng J, Zheng Y, et al. Preparation, characterization and catalytic activity of core-satellite $\mathrm{Au} / \mathrm{Pdop} / \mathrm{SiO} 2 / \mathrm{Fe} 3 \mathrm{O} 4$ magnetic nanocomposites. RSC Adv. 2013;3(33):13818-13824. doi:10.1039/c3ra41537f

51. Dong F, Firkowska-Boden I, Arras MML, Jandt KD. Responsive copolymer-graphene oxide hybrid microspheres with enhanced drug release properties. RSC $A d v$. 2017;7(7):3720-3726. doi:10.1039/ C6RA25353A

52. Shen $\mathrm{L}$, $\mathrm{Li} \mathrm{B}$, Qiao $\mathrm{Y}$. $\mathrm{Fe}_{3} \mathrm{O}_{4}$ nanoparticles in targeted drug/gene delivery systems. Materials. 2018;11(2):324. doi:10.3390/ma11020324

53. Amendola V, Meneghetti M. Size evaluation of gold nanoparticles by UV-vis spectroscopy. J Phys Chem C. 2009;113(11):4277-4285. doi:10.1021/jp8082425

54. Haiss W, Thanh NTK, Aveyard J, Fernig DG. Determination of size and concentration of gold nanoparticles from UV-vis spectra. Anal Chem. 2007;79(11):4215-4221. doi:10.1021/ac0702084

55. Zhao Y, Sadat ME, Dunn A, et al. Photothermal effect on Fe3O4 nanoparticles irradiated by white-light for energy-efficient window applications. Sol Energy Mater Sol Cells. 2017;161:247-254. doi:10.1016/j.solmat.2016.11.039

56. Dunn AW, Ehsan SM, Mast D, et al. Photothermal effects and toxicity of $\mathrm{Fe} 3 \mathrm{O} 4$ nanoparticles via near infrared laser irradiation for cancer therapy. Mater Sci Eng C. 2015;46:97-102. doi:10.1016/ j.msec.2014.09.043

57. Chen Y, Zhang F, Wang Q, et al. The synthesis of LA-Fe3O4@PDAPEG-DOX for photothermal therapy-chemotherapy. Dalton Transactions. 2018;47(7):2435-2443. doi:10.1039/C7DT04080F
58. Robinson JT, Tabakman SM, Liang Y, et al. Ultrasmall reduced graphene oxide with high near-infrared absorbance for photothermal therapy. J Am Chem Soc. 2011;133(17):6825-6831. doi:10.1021/ ja2010175

59. Wang Y, Black KCL, Luehmann H, et al. Comparison study of gold nanohexapods, nanorods, and nanocages for photothermal cancer treatment. ACS Nano. 2013;7(3):2068-2077. doi:10.1021/nn304332s

60. Riley RS, Day ES. Gold nanoparticle-mediated photothermal therapy: applications and opportunities for multimodal cancer treatment. Wiley Interdiscip Rev Nanomed Nanobiotechnol. 2017;9(4):e1449. doi:10.1002/wnan.1449

61. Tong Y, Shao L, Li X, et al. Adhesive and stimulus-responsive polydopamine-coated graphene oxide system for pesticide-loss control. J Agric Food Chem. 2018;66(11):2616-2622. doi:10.1021/acs. jafc. $7 \mathrm{~b} 05500$

62. Zhao $\mathrm{M}, \mathrm{Wu} \mathrm{W}, \mathrm{Su}$ B. $\mathrm{pH}$-controlled drug release by diffusion through silica nanochannel membranes. ACS Appl Mater Interfaces. 2018;10(40):33986-33992. doi:10.1021/acsami.8b12200

63. Murzin DY, Heikkilä T. Modeling of drug dissolution kinetics with sigmoidal behavior from ordered mesoporous silica. Chem Eng Commun. 2014;201(5):579-592. doi:10.1080/00986445.2013.782290

64. Pelin M, Fusco L, Martin C, et al. Graphene and graphene oxide induce ROS production in human HaCaT skin keratinocytes: the role of xanthine oxidase and NADH dehydrogenase. Nanoscale. 2018;10 (25):11820-11830. doi:10.1039/C8NR02933D

65. Soenen SJ, Rivera-Gil P, Montenegro J-M, Parak WJ, De Smedt SC, Braeckmans K. Cellular toxicity of inorganic nanoparticles: common aspects and guidelines for improved nanotoxicity evaluation. Nano Today. 2011;6(5):446-465. doi:10.1016/j.nantod.2011.08.001

66. Alkilany AM, Murphy CJ. Toxicity and cellular uptake of gold nanoparticles: what we have learned so far? J Nanopart Res. 2010;12(7):2313-2333. doi:10.1007/s11051-010-9911-8

67. Khlebtsov N, Dykman L. Biodistribution and toxicity of engineered gold nanoparticles: a review of in vitro and in vivo studies. Chem Soc Rev. 2011;40(3):1647-1671. doi:10.1039/C0CS00018C

68. Pernodet N, Fang X, Sun Y, et al. Adverse effects of citrate/gold nanoparticles on human dermal fibroblasts. Small. 2006;2(6):766773. doi:10.1002/smll.200500492

69. Mironava T, Hadjiargyrou M, Simon M, Jurukovski V, Rafailovich MH. Gold nanoparticles cellular toxicity and recovery: effect of size, concentration and exposure time. Nanotoxicology. 2010;4(1):120137. doi:10.3109/17435390903471463

70. Patra HK, Banerjee S, Chaudhuri U, Lahiri P, Dasgupta AK. Cell selective response to gold nanoparticles. Nanomedicine:NBM. 2007;3 (2):111-119. doi:10.1016/j.nano.2007.03.005

71. Iturrioz-Rodríguez N, Correa-Duarte MA, Fanarraga ML. Controlled drug delivery systems for cancer based on mesoporous silica nanoparticles. Int J Nanomedicine. 2019;14:3389-3401. doi:10.2147/IJN. S198848

72. Hudson SP, Padera RF, Langer R, Kohane DS. The biocompatibility of mesoporous silicates. Biomaterials. 2008;29(30):4045-4055. doi:10.1016/j.biomaterials.2008.07.007

73. Chang B, Guo J, Liu C, Qian J, Yang W. Surface functionalization of magnetic mesoporous silica nanoparticles for controlled drug release. J Mater Chem. 2010;20(44):9941-9947. doi:10.1039/c0jm01237h

74. Iturrioz-Rodriguez N, Gonzalez-Dominguez E, Gonzalez-Lavado E, et al. A biomimetic escape strategy for cytoplasm invasion by synthetic particles. Angewandte Chemie. 2017;56(44):13736-13740. doi:10.1002/anie.201707769

75. Gonzalez-Dominguez E, Iturrioz-Rodriguez N, Padin-Gonzalez E, et al. Carbon nanotubes gathered onto silica particles lose their biomimetic properties with the cytoskeleton becoming biocompatible. Int $J$ Nanomedicine. 2017;12:6317-6328. doi:10.2147/IJN. $\mathrm{S} 141794$ 


\section{Publish your work in this journal}

The International Journal of Nanomedicine is an international, peerreviewed journal focusing on the application of nanotechnology in diagnostics, therapeutics, and drug delivery systems throughout the biomedical field. This journal is indexed on PubMed Central, MedLine, CAS, SciSearch ${ }^{\mathbb{B}}$, Current Contents ${ }^{\mathbb{B}} /$ Clinical Medicine,
Journal Citation Reports/Science Edition, EMBase, Scopus and the Elsevier Bibliographic databases. The manuscript management system is completely online and includes a very quick and fair peer-review system, which is all easy to use. Visit http://www.dovepress.com/ testimonials.php to read real quotes from published authors. 